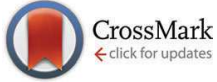

Cite this: J. Mater. Chem. B, 2015, 3, 7831

Received 16th May 2015, Accepted 29th July 2015

DOI: $10.1039 / c 5 t b 00931 f$

www.rsc.org/MaterialsB

\section{Synthesis and design of biologically inspired biocompatible iron oxide nanoparticles for biomedical applications}

\author{
Gozde S. Demirer, ${ }^{a}$ Aysu C. Okur ${ }^{\mathrm{b}}$ and Seda Kizile ${ }^{\star a b}$ \\ During the last couple of decades considerable research efforts have been directed towards the \\ synthesis and coating of iron oxide nanoparticles (IONPs) for biomedical applications. To address the \\ current limitations, recent studies have focused on the design of new generation nanoparticle systems \\ whose internalization and targeting capabilities have been improved through surface modifications. This \\ review covers the most recent challenges and advances in the development of IONPs with enhanced \\ quality, and biocompatibility for various applications in biotechnology and medicine.
}

\section{Introduction}

Nanoscale systems are powerful tools in biotechnology and medicine. They are ideal candidates to improve current clinical diagnostic and therapeutic techniques. Nanoparticles can be composed of several materials such as iron oxide, gadolinium oxide, cadmium selenide based quantum dots, and crystals of gold. ${ }^{1-5}$ Among these, iron oxide nanoparticles (IONPs) have attracted significant attention, especially for biomedical applications, due to their properties like biocompatibility, low toxicity, stability, availability for surface modification, and higher relaxation values. ${ }^{6-10}$ For in vivo applications, maghemite $\left(\mathrm{Fe}_{2} \mathrm{O}_{3}\right)$ and magnetite $\left(\mathrm{Fe}_{3} \mathrm{O}_{4}\right)$ forms of iron oxide have been commonly preferred for being

${ }^{a}$ Koc University, Chemical and Biological Engineering, Istanbul 34450, Turkey. E-mail: skizilel@ku.edu.tr; Fax:+90-212-338-1548; Tel: +90-212-338-1836

${ }^{b}$ Koc University, Biomedical Science and Engineering, Istanbul 34450, Turkey metastable compared to other forms of iron oxide, and due to their capability to form a continuous solid solution together with each other. ${ }^{11}$ However, protocols for synthesis are complicated due to the colloidal character of IONPs. The monodispersity, size, shape and surface properties all play crucial roles in the synthesis, as these properties influence the colloidal stability of nanoparticles significantly.

Without any surface adjustment, IONPs tend to agglomerate due to their high surface area to volume ratio, and aggregation results in fast detection of nanoparticles by the immune system. To overcome aggregation and provide high colloidal stability, coating of IONPs has been usually considered. Coating is also a key task to eliminate the limitations associated with the utilization of IONPs in biomedicine. For instance, an appropriate coating material can result in dispersion of nanoparticles in a biological environment, and hence allows for further functionalization of the surface, improves compatibility in blood, prevents

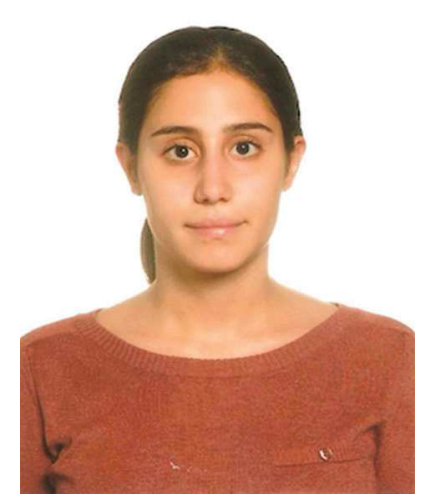

Gozde S. Demirer received her BSc degree in Chemical and Biomolecular Engineering from Koc University (Istanbul, Turkey) in 2015. Starting from this fall, she will continue her studies at UC Berkeley with the PhD program in Chemical Engineering. Her research focuses on developing novel nanomaterials for cancer diagnosis and therapy.

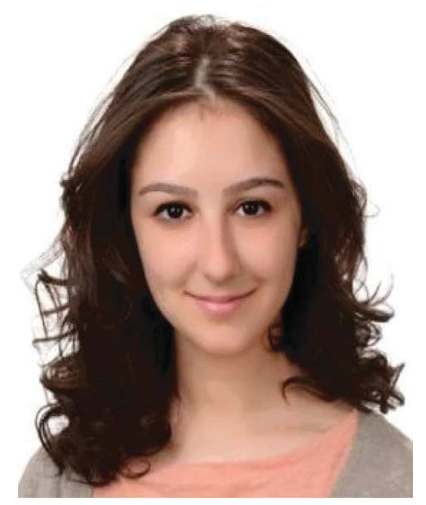

Ms Aysu C. Okur graduated from Materials Science and Engineering from Sabancl University in 2013 (Istanbul, Turkey). Currently, she has been doing her master studies on Biomedical Engineering at Koc University (Istanbul, Turkey) focusing on drug delivery. Her research interests include synthesis, electronic, optic and biomedical applications of nanomaterials.

Gozde S. Demirer

Aysu C. Okur 
non-specific adsorption of plasma proteins on nanoparticles, and can retard degradation by macrophages. ${ }^{12-15}$ Moreover, uncoated IONPs can get easily oxidized in air, resulting in loss of magnetism and colloidal stability. ${ }^{16}$ Coating can be achieved through polymeric materials such as dextran, polyethylene glycol (PEG), polyvinyl alcohol (PVA), chitosan, and starch. ${ }^{10,17-21}$ Moreover, some inorganic materials such as gold and silica have been used for coating purposes. ${ }^{22,23}$ Recently, it has been found that nonpolymeric organic materials such as oleic acid, carboxylates and alkyl phosphonates can also be used for coating of IONPs. ${ }^{23}$

IONPs smaller than $20 \mathrm{~nm}$ have superparamagnetic properties, and are known as superparamagnetic iron oxide nanoparticles (SPIONs). Superparamagnetism is crucial for many applications in biomedicine, because when an external magnetic field is removed, superparamagnetic materials do not retain any magnetism. Therefore, SPIONs have great potential for a variety of biomedical applications, such as early detection of inflammatory cancer and diabetes, magnetic resonance imaging (MRI), hyperthermia, gene therapy, stem cell tracking, tissue repair, and manipulation of cell organelles. ${ }^{10,11,24-28}$ In addition to these applications, recent studies have demonstrated the promising role of surface functionalized SPIONs in targeted/site specific drug delivery. ${ }^{29-31}$ The targeting capabilities of magnetic nanoparticles can be reinforced through immobilization of specific ligands on a surface, which is expected to promote the affinity of nanoparticles towards the sites of interest. These ligands are generally peptides, proteins, polysaccharides, antibodies, and aptamers. ${ }^{32-36}$ Moreover, by selecting an appropriate ligand, internalization of nanoparticles by the targeted cells can be significantly improved. ${ }^{37}$ In addition, intracellular delivery of therapeutic drugs could be achieved through the design of stimuli responsive coatings around nanoparticles. These new generation nanoparticle systems are superior over non-targeted approaches, hence these systems are expected to address current limitations of cancer therapeutics such as non-specific distribution of drugs in the body, undesirable side effects due to requirement of a large dose to obtain high

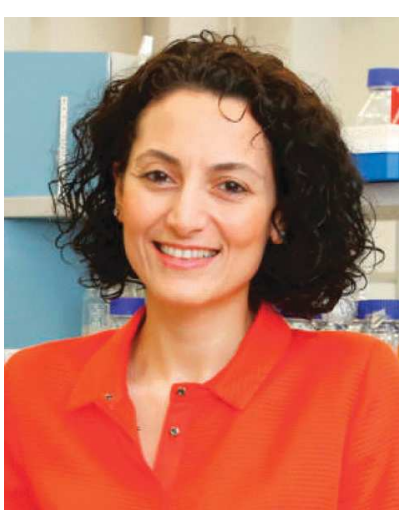

Seda Kizilel
Seda Kizilel received her BS and MS degrees in Chemical Engineering from Bogazici University (Istanbul, Turkey). She completed her PhD in Biomedical Engineering from Illinois Institute of Technology in 2004, and postdoctoral studies at the University of Chicago, between 2004 and 2007. She has been working as an Associate professor in Chemical and Biological Engineering program at Koc University (Istanbul, Turkey), since 2008. Dr Kizilel is interested in designing biomaterials for tissue engineering, developing micro/ nanoparticles for targeted drug delivery, and immunoisolation of insulin secreting pancreatic islets for the treatment of type 1 diabetes. local drug concentration, resistance of cancer cells to drugs, and non-specific toxicity.

\section{Synthesis of IONPs}

Synthesis of magnetic IONPs with desirable properties had long been a challenge for researchers. Researchers were mainly confronted with two challenges: the first one involved efforts related to the optimization of experimental conditions, which generated monodispersed particles with suitable size. The second difficulty was related to the development of a reproducible procedure, where complex purification steps such as ultracentrifugation, magnetic filtration or size-exclusion chromatography would be avoided. For the conditions where the product does not have homogenous composition or narrow size distribution, these kinds of further purification methods become necessary, because monodispersity, shape, and size are crucial factors that determine the clinical potential of nanoparticles. ${ }^{10,23}$ With significant progress, numerous techniques have been reported, where efficient synthesis resulted in stable, biocompatible, and monodispersed nanoparticle population. These techniques resulted in the development of high quality IONPs with controlled size and shape features. The most common methods for the formation of IONPs are co-precipitation of iron salts, microemulsion formation, hydrothermal synthesis, and thermal decomposition of iron precursors. Other techniques such as electrochemical synthesis, sonochemical reactions, sol-gel synthesis, and laser pyrolysis methods have been utilized over time to synthesize magnetic nanoparticles. ${ }^{38-41}$ In this review, co-precipitation, microemulsion, hydrothermal synthesis, and thermal decomposition methods for the synthesis of IONPs have been explained in detail and their features are compared in Table 1.

\subsection{Co-precipitation method}

To produce IONPs, the co-precipitation method has been commonly preferred due to its simplicity and fast rate of production. It is a reduction reaction of iron salts under alkaline conditions to produce magnetite $\left(\mathrm{Fe}_{3} \mathrm{O}_{4}\right)$ or maghemite $\left(\mathrm{Fe}_{2} \mathrm{O}_{3}\right)$. To synthesize the magnetite form of iron oxide, aqueous solutions of ferric $\left(\mathrm{Fe}^{3+}\right)$ and ferrous $\left(\mathrm{Fe}^{2+}\right)$ ions have to be mixed in a $2: 1$ molar ratio, and precipitated by addition of a base. For efficient magnetite production, the $\mathrm{pH}$ of the solution should be between 9 and 14 . The precipitated solution retains black color after the reaction. The overall chemical reaction for magnetite formation is as follows:

$$
\mathrm{Fe}^{2+}+2 \mathrm{Fe}^{3+}+8 \mathrm{OH}^{-} \rightarrow \mathrm{Fe}_{3} \mathrm{O}_{4}+4 \mathrm{H}_{2} \mathrm{O}
$$

This reaction has to be conducted in an oxygen-free environment, because magnetite is not stable enough, and it is prone to remain in the oxidated state. ${ }^{23}$ Magnetite is converted to maghemite in the presence of oxygen as follows:

$$
\mathrm{Fe}_{3} \mathrm{O}_{4}+2 \mathrm{H}^{+} \rightarrow \gamma \mathrm{Fe}_{2} \mathrm{O}_{3}+\mathrm{Fe}^{2+}+\mathrm{H}_{2} \mathrm{O}
$$

In the presence of oxygen, magnetite $\left(\mathrm{Fe}_{3} \mathrm{O}_{4}\right)$ particles can also be converted into $\mathrm{Fe}(\mathrm{OH})_{3}$ through the following reaction: ${ }^{11}$

$$
\mathrm{Fe}_{3} \mathrm{O}_{4}+0.25 \mathrm{O}_{2}+4.5 \mathrm{H}_{2} \mathrm{O} \rightarrow 3 \mathrm{Fe}(\mathrm{OH})_{3}
$$


Table 1 Comparison of the iron oxide nanoparticle synthesis methods

\begin{tabular}{lllllll}
\hline Synthesis method & Operation & Temperature $\left({ }^{\circ} \mathrm{C}\right)$ & Duration & Size distribution & Shape control & Dispersity profile \\
\hline Co-precipitation & Simple, ambient & $20-90$ & Minutes & Not narrow & Not good & Polydisperse \\
Microemulsion & Complicated, ambient & $20-50$ & Hours & Relatively narrow & Good & Relatively monodisperse \\
Hydrothermal synthesis & High pressure temperature & $\sim 220$ & Hours & Very narrow & Very good & Monodisperse \\
Thermal decomposition & Complicated, inert atm. & $100-320$ & Days & Very narrow & Very good & Monodisperse
\end{tabular}

This oxidation/reduction preference of iron ions inevitably affects the physical and chemical properties of nanoparticles. Therefore, a precipitation reaction has to be conducted under an inert gas environment. For example, $\mathrm{N}_{2}$ gas treatment of the reaction mixture or coating the nanoparticles during the precipitation process can prevent deterioration of $\mathrm{Fe}_{3} \mathrm{O}_{4}$. It is also observed that the reactions performed under an oxygenfree environment result in nanoparticles with smaller particle sizes. ${ }^{16}$ By changing the type of salt used (such as chlorides, sulfates, nitrates, perchlorates, etc.), the ferric and ferrous ion ratio, the reaction temperature, the $\mathrm{pH}$ value of the solution, ionic strength of the media and size and shape of the nanoparticles can be controlled. ${ }^{42}$ Although the co-precipitation method is easy, fast, and available for a large amount of production, it generates nanoparticles with a wide particle size distribution. To avoid the size polydispersity, many studies have been performed. For example, W. Jiang et al. reported a co-precipitation synthesis method, where they were able to control the size and homogeneity of nanoparticles produced. ${ }^{43}$ Briefly, they manipulated the $\mathrm{pH}$ of the ferrite solution homogeneously by using urea. Before adding base to precipitate the iron salts in the solution, urea was decomposed by heating. Uniform $\mathrm{pH}$ distribution of the ferrite solution resulted in uniform particle size after precipitation. The mechanism of the reaction is as follows: ${ }^{43}$

$$
\begin{gathered}
\mathrm{CO}(\mathrm{NH})_{2}+\mathrm{H}_{2} \mathrm{O} \stackrel{\Delta}{\longrightarrow} 2 \mathrm{NH}_{3}+\mathrm{CO}_{2} \\
\mathrm{NH}_{3}+\mathrm{H}_{2} \mathrm{O} \rightarrow \mathrm{NH}_{4}^{+}+\mathrm{OH}^{-}
\end{gathered}
$$

Decomposition of urea around $90{ }^{\circ} \mathrm{C}$ produces ammonia, and ammonia in water generates hydroxyl ions which increase the $\mathrm{pH}$ throughout the solution. For example, W. Jiang et al. altered the amount of urea decomposed to obtain monodisperse nanoparticle population, which resulted in controlled IONP size. ${ }^{43}$

\subsection{Microemulsion method}

The co-precipitation method generally generates polydispersed particles; hence, other techniques with more control over nanoparticle dimensions have been developed. The microemulsion method is one of the alternative methods generating IONPs with tunable size and distribution properties. Microemulsion is defined as a thermodynamically stable isotropic dispersion of two immiscible liquids in the presence of an appropriate surfactant. To synthetize IONPs with narrow size range and uniform physical properties, water-in-oil reverse micelles have been commonly employed. Sodium bis(2-ethylhexylsulfosuccinate) (AOT), cetyltrimethylammonium bromide (CTAB), and sodium dodecyl sulfate (SDS) have been commonly reported as surfactants used for the synthesis of IONPs in the literature. ${ }^{23}$ Surfactant molecules create a monolayer at the interface of water and oil, where this monolayer is formed by dissolution of hydrophobic parts of surfactant molecules in the oil phase, and dissolution of hydrophilic groups in the aqueous phase (Fig. 1). ${ }^{16}$ In this method, an aqueous solution of iron salts can be dissolved in the core of the reverse micelle, and a precipitation reaction can be carried out inside the aqueous core. Hence, by controlling the aqueous micellar core size, the nanoparticle size can be adjusted.

Gupta and Wells reported the synthesis of SPIONs with narrow particle size distribution by using AOT $/ n$-hexane reverse micelles in a $\mathrm{N}_{2}$ environment. ${ }^{44}$ In this study, the size of the reverse micelle core was within the nanometer range, so SPIONs with small size (around $15 \mathrm{~nm}$ ) with narrow size distribution were obtained. Vidal-Vidal et al. have reported the synthesis of SPIONs with a size distribution of $3.5 \pm 0.6 \mathrm{~nm}$ with high magnetization values by using a microemulsion of cyclohexane/Brij-97/aqueous phase. ${ }^{45}$ Although the microemulsion method provides relatively good shape control and size distribution, the potential toxicity of surfactants makes this process non-biocompatible. Also, the synthesized nanoparticles require further stabilization steps due to their aggregation and colloidal instability. ${ }^{16}$
A)

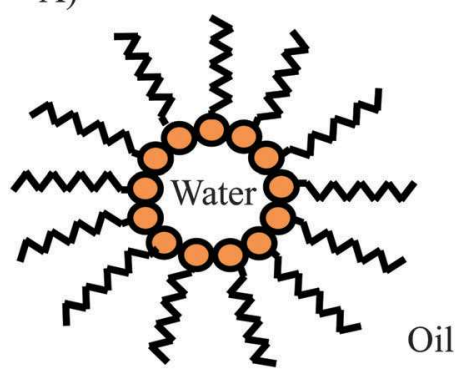

B)

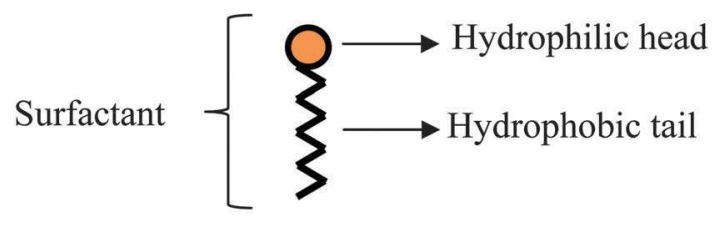

Fig. 1 (A) Structure of a reverse micelle in water-in-oil, (B) structure of the surfactant. 


\subsection{Hydrothermal synthesis method}

The hydrothermal synthesis method is a commonly used method to produce IONPs with narrow size distribution and good shape control. Hydrothermal synthesis reactions are performed in a sealed container or an autoclave at high temperature and pressure. Reactions that occur in aqueous solutions at high temperatures (130-250 ${ }^{\circ} \mathrm{C}$ ) and high pressures (0.3-4 MPa) result in monodispersed, small sized nanoparticles with a high degree of crystallinity. ${ }^{16}$ Based on previous studies, it is well-established that a high degree of crystallinity, size and shape homogeneity, and decrease in agglomeration are the most important features of the nanoparticles synthesized by the hydrothermal method. ${ }^{46}$

Two types of hydrothermal synthesis methods have been reported in the literature: one approach involves the use of surfactants, whereas the other method is based on the synthesis without surfactants. For example, Ge et al. reported a facile hydrothermal synthesis method for IONPs with tunable magnetic properties in the absence of a surfactant. ${ }^{47} \mathrm{Fe}_{3} \mathrm{O}_{4}$ nanoparticles with an average size of $31.1 \pm 6.1 \mathrm{~nm}$ were obtained from $\mathrm{Fe}^{2+}$ ion precipitation with ammonium hydroxide, followed by an autoclave step at $134{ }^{\circ} \mathrm{C}$, for 3 hours at 2 bars. The size of IONPs, and hence their magnetic properties, were altered by changing the concentration of the reactants and the reaction solvent composition. In contrast, Zheng et al. synthesized IONPs with $27 \mathrm{~nm}$ size by a hydrothermal method in the presence of AOT surfactant. ${ }^{48}$ After the precipitation of $\mathrm{Fe}^{3+}$ ions, the reaction mixture (with the surfactant) is held at $160{ }^{\circ} \mathrm{C}$ for 10 hours. The results showed that this procedure led to synthesis of nanoparticles with superparamagnetic behavior at room temperature.

The hydrothermal synthesis method is one of the oldest methods to synthesize IONPs; however, various improvements have been reported by many researchers. This method has been extended to produce SPIONs by using electromagnetic radiation with microwaves. ${ }^{49}$ For instance, R. Y. Hong et al. produced $\mathrm{Fe}_{3} \mathrm{O}_{4}$ nanoparticles with an average diameter of $10 \mathrm{~nm}$ through hydrothermal synthesis under microwave irradiation. ${ }^{50}$ The mixture of $\mathrm{Fe}^{2+}$ and $\mathrm{Fe}^{3+}$ is precipitated by $\mathrm{NH}_{4} \mathrm{OH}$, and $\mathrm{N}_{2} \mathrm{H}_{2}$. $\mathrm{H}_{2} \mathrm{O}$ was used as an oxidation-resistant agent. Reactions were carried out inside a microwave oven where irradiation was maintained at a frequency of $2.5 \mathrm{GHz}$. The results demonstrated that the SPIONs produced were monodispersed, and had high magnetization property at room temperature.

\subsection{Thermal decomposition}

Another method to produce high quality IONPs with narrow size distribution and high crystallinity is thermal decomposition of organometallic precursors through organic solvents and surfactants. Common organometallic precursors reported in the literature included $\mathrm{Fe}(\text { cup })_{3}$ (cup $=N$-nitrosophenylhydroxylamine), $\mathrm{Fe}(\mathrm{acac})_{3}$ (acac $=$ acetylacetonate $)$ and $\mathrm{Fe}(\mathrm{CO})_{5} \cdot{ }^{16}$ As surfactants oleylamine, fatty acids, oleic acid, hexadecylamine, and steric acid have been commonly utilized. ${ }^{10}$ For example, Hyeon and coworkers applied a two-step process to generate SPIONs within the size range of 4-16 nm. ${ }^{51}$ First, monodispersed maghemite at $100{ }^{\circ} \mathrm{C}$ by thermal decomposition of iron pentacarbonyl in the presence of oleic acid was obtained, next iron-oleic complex at $300{ }^{\circ} \mathrm{C}$ was aged, which resulted in the formation of high quality SPIONs at room temperature.

Size and shape features of the produced SPIONs can be controlled by altering the reaction temperature, concentration of the reactants, solvent properties, and precursor type, and duration. ${ }^{23}$ Since the thermal decomposition method results in highly monodispersed particles with a narrow size distribution, SPIONs generated by this method can be used in biomedical applications such as magnetic resonance imaging, magnetic cell separation or magnetorelaxometry. ${ }^{52}$ This method generally requires relatively high temperatures and a complicated operation; however, its main disadvantage is the generation of nanoparticles that can be only dissolved in nonpolar solvents. ${ }^{16}$ Sun and colleagues eliminated this limitation by transforming hydrophobic nanoparticles into hydrophilic ones through addition of bipolar surfactants. They produced monodisperse magnetite nanoparticles with particle diameter ranging from 3 to $20 \mathrm{~nm}$ by decomposing iron(III) acetylacetonate, $\mathrm{Fe}(\mathrm{acac})_{3}$, with 1,2hexadecanediol in the presence of oleic acid and oleylamine. ${ }^{12}$ Then, they added hexane a dispersion of hydrophobic $\mathrm{Fe}_{3} \mathrm{O}_{4}$ nanoparticles into a suspension of tetramethylammonium 11aminoundecanoate in dichloromethane to make them hydrophilic. As a result, they obtained particles with superparamagnetic properties at room temperature with hydrophilic properties.

\section{Coating of iron oxide nanoparticles within natural/synthetic polymers}

The stability of IONPs has extreme importance for synthesis, storage and usage. Bare nanoparticles have the tendency to agglomerate and form clusters to reduce their large surface area to volume ratio. Therefore, surface coating is necessary to impart colloidal stability and prevent agglomeration. In addition, by selecting appropriate coating type, further functionalization and targeting can be achieved, and nanoparticles can be designed as soluble in biological media. Some of the desirable properties of coating materials have been known as: high chemical affinity of iron oxide core, non-immunogenecity, non-antigenecity, and protection from opsonization by plasma proteins. ${ }^{36}$

Among the many different types of polymeric coating materials that have been utilized in the literature, we have focused on coatings with polyethylene glycol (PEG), polyvinyl alcohol (PVA), chitosan, and dextran in this review, as these polymeric materials have been most commonly used in previous studies (Fig. 2). ${ }^{53}$

\subsection{Polyethylene glycol (PEG)}

PEG is a synthetic polymer, which is used frequently in nanoparticle functionalization due to the advantages it provides especially for biomedical applications. Firstly, it is a hydrophilic biocompatible polymer, therefore has the capability to be dissolved in water. The biocompatibility of PEG has been approved by the US Food and Drug Administration (FDA). ${ }^{54}$ Secondly, many researchers have reported that PEG increases the biocompatibility of iron oxide nanoparticles, and eliminates fast blood clearance. 


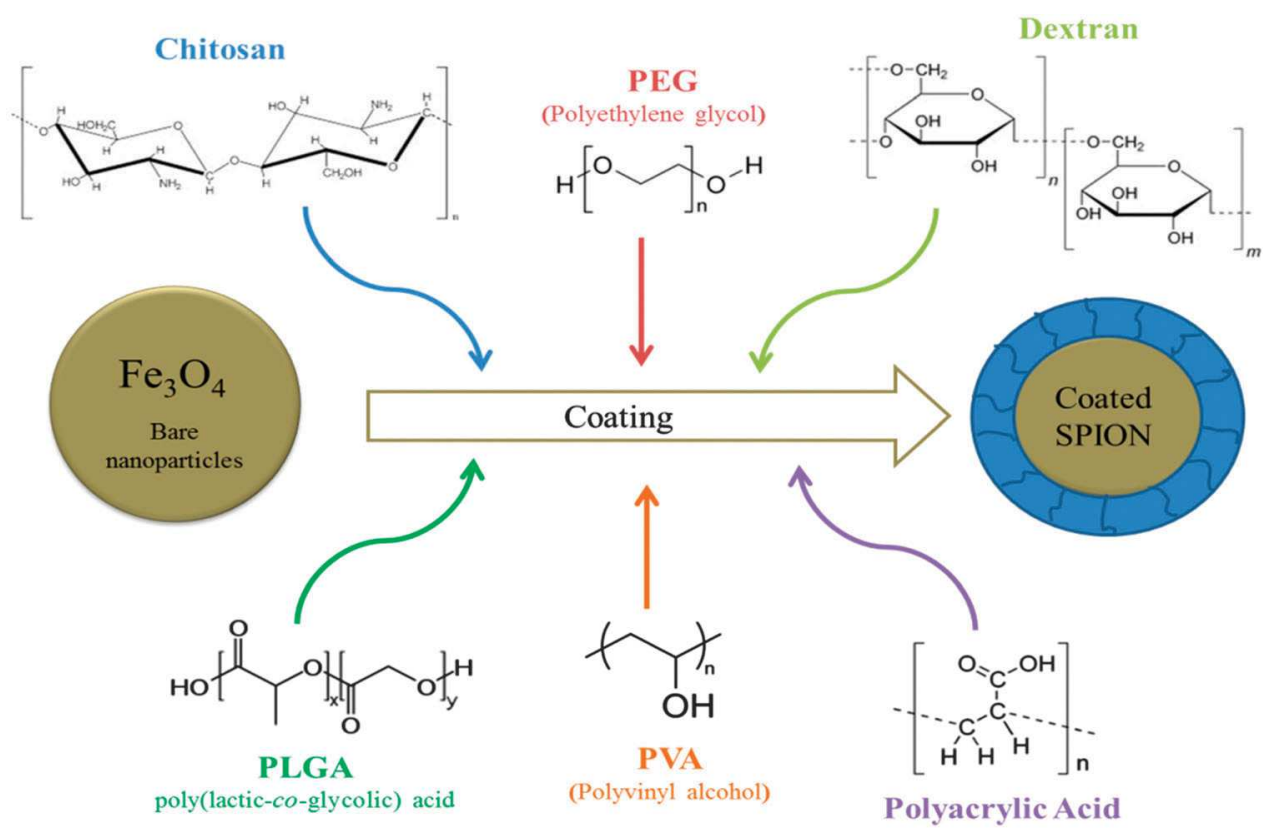

Fig. 2 Coating scheme of bare iron oxide nanoparticles.

Therefore, it increases the blood circulation time of nanoparticles, which may be very beneficial in drug release applications. Moreover, PEG coating increases the internalization efficiency of nanoparticles into the cells. ${ }^{55}$ Beside its excellent solubility and stability in aqueous solutions, it is also stable in physiological saline solutions. ${ }^{23}$ The only drawback of coating with PEG is that it is not biodegradable in the human body and metabolic clearance of PEG has not yet been fully discovered. ${ }^{56}$

Coating within PEG can be achieved either during or after the synthesis of nanoparticles. Studies have revealed that nanoparticles which are coated after the synthesis show better dispersion profiles than nanoparticles coated during the synthesis reactions. ${ }^{57}$ Various methods have been reported in the literature for the coating of IONPs within polyethylene glycol. M. Anbarasu et al. have reported a facile route to synthesize PEG coated $\mathrm{Fe}_{3} \mathrm{O}_{4}$ nanoparticles by a chemical co-precipitation method. ${ }^{58}$ In this method, PEG was mixed with ferric sulfate and ferrous sulfate in the precursor, which was then precipitated together by addition of base. A. Masoudi et al. have reported a two-step approach consisting of IONP synthesis through a co-precipitation method, followed by PEG coating by adding a PEG solution to an iron oxide suspension and stirring for 24 hours via a mechanical stirrer. ${ }^{59}$ C. Nazli et al. have reported the synthesis of PEG hydrogel coated IONPs through surface-initiated photopolymerization reactions. ${ }^{31}$ In this method, IONPs were suspended in a prepolymer solution composed of PEG, accelerator, initiator and water, which was then exposed to green light by using an argon ion laser to conduct the photopolymerization reaction.

\subsection{Polyvinyl alcohol (PVA)}

PVA is another common coating material for biomedical applications due to several reasons. Firstly, it is hydrophilic and biocompatible. Secondly, it has low toxicity and prevents agglomeration of nanoparticles in the biological media. ${ }^{23,55}$ Additionally, synthesis methods that are carried out in the presence of PVA result in the formation of monodispersed particles. Moreover, due to the multi-hydroxyl structure of PVA, its crystallinity is enhanced, resulting in desirable thermo-mechanical properties such as high elastic modulus, crystallinity and tensile strength in bio-related applications. ${ }^{55,60}$ The most interesting fact about PVA is the protection of its elastic modulus even with high water content in applications such as hydrogels. Therefore, it is applicable to various interests from drug delivery to wound healing. ${ }^{61}$ However, it has been demonstrated that PVA coated IONPs have limitations in tissue distribution and penetration. ${ }^{14}$

Several methods have been reported in the literature for the successful coating of IONPs within polyvinyl alcohol. Similar to coating with PEG, PVA coating can be achieved either during or after the synthesis of nanoparticles. H. Pardoe et al. reported the coating of IONPs within PVA during the co-precipitation reaction by the addition of base. ${ }^{62}$ On the other hand, many studies have reported a two-step approach to coat IONPs with PVA. M. Mahmoudi et al. have synthesized iron oxide nanoparticles through the precipitation of iron salts under an argon atmosphere, and coated them by adding the PVA solution (polymer to iron mass ratio of 2) with a reaction of 30 minutes at $35{ }^{\circ} \mathrm{C}$ and $3600 \mathrm{rpm} .{ }^{63}$ Other studies have also used the same method with different reaction times, temperatures, PVA amounts and stirring rates. ${ }^{64,65}$

\subsection{Chitosan}

Chitosan is a cationic polysaccharide similar to cellulose in structure. It is composed of 2-amino-2-deoxy-h-D-glucan combined with glycosidic linkages. Due to primary amine groups, chitosan has been commonly preferred in pharmaceutical applications. It is also greatly preferred in drug delivery applications due to its 
mucoadhesive property and positive charge. Under basic or neutral $\mathrm{pH}$ conditions, chitosan is not water-soluble; however, in acidic $\mathrm{pH}$ amino groups are protonated, which make chitosan water-soluble. Chitosan is biocompatible, and does not elicit an allergic reaction. It is also biodegradable, where degradation products are nontoxic amino sugars. ${ }^{23}$ Moreover, it has antimicrobial properties and absorbs toxic materials. Finally, it demonstrates adhesive properties and immuno-stimulating activity. ${ }^{66}$ With these properties, it is suitable for affinity protein purification and magnetic bioseparation. Due to these features, IONPs coated with chitosan have been considered to be promising for various tissue engineering applications. ${ }^{67}$

There are many studies on chitosan coating of iron oxide nanoparticles for biomedical applications. J. Castelló et al. reported the synthesis of $12 \mathrm{~nm}$ IONPs via a controlled co-precipitation method, and coated the particles with chitosan. ${ }^{68}$ The results demonstrated that chitosan coated IONPs had superparamagnetic properties and they were suitable for biomedical applications. H. Shagholani et al. synthesized IONPs that were coated by chitosan and then modified the surface of the particles with PVA. ${ }^{69}$ Due to its surface zeta potential value, this hybrid coating system had low protein adsorption and hence is promising for in vivo drug delivery applications and for clinical trials.

\subsection{Dextran}

Dextran is an important material for coating iron oxide nanoparticles, and has been used in fundamental applications such as MRI, cancer imaging and treatments. ${ }^{11,36}$ To date, dextran coating on SPIONs has been used in the MRI of liver, and clinically approved, as it prevents nanoparticle aggregation. ${ }^{70}$ Dextran is a biocompatible material, but it is not degradable in the human body. The enzyme which degrades dextran, dextranase, cannot be not synthesized by human cell lines. ${ }^{11}$ However, one of the main disadvantages of dextran coating is the weak bond of dextran with the IONP surface, which may influence the applications negatively. ${ }^{36}$ Another concern about dextran is its adverse effect on compound tolerance resulting in limited infusion in a slow manner. ${ }^{71}$

Various studies have been reported in the literature about the dextran coating of IONPs for biomedical applications. Josephson et al. synthesized monocrystalline iron oxide nanoparticles coated with dextran to improve the intracellular magnetic labeling of different target cells. ${ }^{72}$ To crosslink dextran and prevent dissociation under certain biological conditions, IONPs were treated with epichlorohydrin. To allow further functionalization of the surface to attach targeting ligands, particles were also treated with ammonia. Results showed that derivatized particles were internalized into cells over 100-fold more efficiently than non-modified particles. ${ }^{72}$ In another study, A. Jafari et al. reported the synthesis of dextran coated IONPS that were conjugated with bombesin to produce a targeting contrast agent for detection of breast cancer using MRI. ${ }^{73}$ The synthesis of $6 \mathrm{~nm}$ dextran coated IONPs was done via a one step co-precipitation method in which dextran was mixed with the iron salts to be precipitated with ammonia addition. The results demonstrated that this system possessed good diagnostic ability in mice with breast tumors. ${ }^{73}$

\section{Coating of iron oxide nanoparticles within non-polymeric materials}

To provide colloidal stability and to prevent agglomeration of IONPs, non-polymeric coating materials have also been used in addition to polymers. Among the many different types of nonpolymeric coating materials reported in the literature, we have focused on coatings with silica and gold as these inorganic materials have been most commonly used in previous studies.

\subsection{Silica}

Silica is one of the most common inorganic material that is used to functionalize IONPs. ${ }^{74}$ There are numerous advantages of silica coating for magnetite nanoparticles. First, silica prevents aggregation of nanoparticles, and improves the chemical stability of particles. Second, silica reduces the toxicity of nanoparticles, which will contribute to their biocompatibility. ${ }^{23,74}$ Moreover, silica possesses a hydrophilic structure, and hence helps in binding various biological ligands. Another advantage of silica in terms of processing is related to the facile functionalization of IONPs with silica. IONPs that are functionalized with silica are very promising in applications for catalysis, biolabeling, bioseparation, and some commercial applications such as ferrofluidics. ${ }^{74,75}$ However, the main limitation of coating with silica is that it is hard to obtain a uniform silica shell thickness. Unequal thickness gives rise to an irregular magnetic field, which causes uneven heating in hyperthermia applications. ${ }^{76}$

Santra et al. used the water in oil microemulsion method to synthesize uniform sized IONPs with a diameter of 1-2 nm, and coated the particles with a thin silica layer of $1 \mathrm{~nm}$ to produce useful magnetic probes for the separation of target oligonucleotides. ${ }^{77}$ Coating was achieved via the base-catalyzed hydrolysis of tetraethyl orthosilicate (TEOS) that produced silicic acid, which underwent a polymerization reaction and formed the silica coating. The study demonstrated successful attachment of DNA molecules onto IONPs. $^{77}$

\subsection{Gold}

Gold-coated magnetic nanoparticles were first reported in 2001 by Lin et $a .^{78}$ Gold has been used to protect iron oxide cores against oxidation, where gold and iron oxide particles together generate particles with high colloidal stability. Gold coating may also be preferred since nanogold is well known for its optical properties. Therefore, gold coated iron oxide nanoparticles have been designed to strongly absorb light. ${ }^{11}$ Gold is biocompatible, and has a high capacity for functionalization. These properties make gold particularly attractive for surface modification of IONPs. One drawback is related to the attenuation in magnetic property of IONP with gold coating, and difficulty in maintenance of coating due to the interaction of two dissimilar surfaces. However, gold-coated IONPs have been characterized as stable under neutral and acidic $\mathrm{pH}$ conditions. ${ }^{67}$ 
G. Liang et al. reported the synthesis of a biosensing system for human alpha thrombin that consists of gold-coated iron oxide nanoparticles. ${ }^{79}$ In this study, IONPs were synthesized via a co-precipitation method and gold coating was achieved by iterative reduction of $\mathrm{HAuCl}_{4}$ onto dextran-coated $\mathrm{Fe}_{3} \mathrm{O}_{4}$ nanoparticles. Results proved that this system was sensitive and successful to detect the human $\alpha$-thrombin. In another study, Mohammad et al. utilized gold-coated IONPs for hyperthermia application. $^{80}$

\section{Biomedical applications of bio-inspired IONPs}

IONPs have been used for various biomedical applications including magnetic resonance imaging (MRI), photoacoustic imaging, cell tracking, bioseparation, magnetic fluid hyperthermia, gene delivery, drug delivery, tissue repair, and manipulation of cellular organelles during the last couple of decades. Recently, new techniques have been developed to functionalize nanoparticles for clinical applications. In this section, these approaches, their current limitations, and developments have been explained in detail.

\subsection{Imaging applications of IONPs}

5.1.1 Magnetic resonance imaging (MRI). Applications of magnetic resonance imaging have increased over the past decade. MRI drugs have to enhance image contrast between normal and diseased tissue to differentiate healthy and pathological tissues, and many different contrast agents have been suggested for this purpose. To date, paramagnetic contrast agents have been utilized in MRI studies, such as paramagnetic gadolinium chelates. ${ }^{52}$ These agents work by shortening the $T_{1}$ relaxation time (longitudinal relaxation time) of water in tissues. On the other hand, superparamagnetic nanoparticles increase the diagnostic sensitivity and specificity due to their superior properties, such as higher molar relaxivities, and capability to shorten both $T_{1}$ relaxation time and $T_{2}$ transversal relaxation time. ${ }^{81}$ The efficiency of these particles depends on their size, charge and coating properties, and can be improved through further modification of their surface with biologically active substances like antibodies, receptor ligands, polysaccharides, and proteins. ${ }^{56,82-86}$

Some SPIONs have been approved for clinical use such as Feridex, Resovist, Sinerem, and Clariscan in the past. ${ }^{87}$ Feridex has been used for liver imaging and cellular labeling. Its hydrodynamic size is approximately $120 \mathrm{~nm}$ with dextran coating. Resovist, which is coated by carboxydextran, is also used for liver imaging with its $60 \mathrm{~nm}$ hydrodynamic size. Sinerem has more applications in the metastatic lymph node imaging, macrophage-imaging areas, and used as a blood pool agent. The size of Sinerem alters between 15 and $30 \mathrm{~nm}$ including dextran coating. Clariscan, with a coating of around $20 \mathrm{~nm}$, has been coated with pegylated starch, and used as a blood pooling agent. ${ }^{23}$ However, these commercial contrast agents do not have further modification potential for tissue targeting purposes. Recently, many studies have concentrated on creating novel MRI contrast agents, where various strategies have been used to achieve targeting capacity. ${ }^{88}$ For example, S. Boutry et al. targeted endothelial inflammatory adhesion molecule E-selectin with a superparamagnetic MRI contrast agent coated with dextran. ${ }^{89}$ The contrast agent was further functionalized by the addition of a synthetic mimetic of sialyl Lewisx, a natural ligand of E-selectin expressed in leukocytes. Both in vitro (on cultured human umbilical vein endothelial cells) and in vivo (on a mouse model of hepatitis) results proved that this new contrast agent recognizes endothelial E-selectin. Therefore, it is suitable for the MRI diagnosis of inflammation. ${ }^{89}$

Yu et al. reported a novel MRI contrast agent for in vivo cancer imaging. ${ }^{90}$ Although the contrast agent does not possess any targeting ligand on its surface, it can accumulate in tumor cells due to an anti-biofouling polymer that is thermally cross-linked with SPIONs (Fig. 3). Coating layers on the nanoparticle increase permeability and retention effect, which provides efficient tumor detection. This new contrast agent can also deliver anticancer drugs to tumors with high efficiency. Therefore, utilizing this contrast agent as a drug-delivery carrier may be beneficial for both cancer imaging and therapy. In vivo studies on animal models proved that high amount of SPIONs accumulated within the tumor environment, and in vitro drug release kinetics showed that $60 \%$ of the drug could be released within 50 minutes. ${ }^{90}$

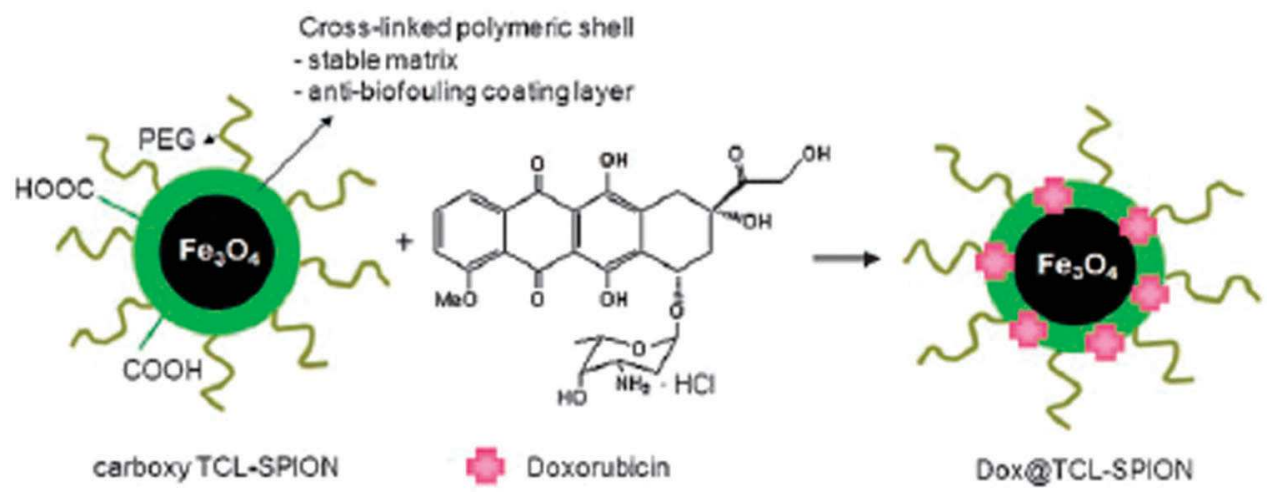

Fig. 3 Image of DOX conjugated anti-biofouling polymer coated thermally cross-linked SPIONs ${ }^{1}$ (reprinted (adapted) with permission from M. K. Yu, J. Park, S. Park, S. Jon, Y. Y. Jeong, J. W. Kim, J. J. Min and K. Kim, Angew. Chem., Int. Ed., 2008, 47, 5362-5365. Copyright (2008) Wiley). 
Yang et al. reported the synthesis of multifunctional SPIONs for targeted drug delivery and positron emission tomography/ magnetic resonance imaging. ${ }^{91}$ Doxorubicin (DOX), tumor targeting ligands, $\mathrm{cRGD}$, and $\mathrm{PET}{ }^{64} \mathrm{Cu}$ chelators were conjugated onto the PEGylated SPIONs. The effectiveness of this system as an MRI contrast agent was tested by an in vitro MRI relaxivity measurement. Results showed that these new contrast agents could accumulate in tumor areas more than that of cRGD free forms, and the MRI relaxivity of agents was close to the Feridex relaxivity value (Fig. 4A). Therefore, these multifunctional SPIONs can be both utilized for cancer therapy and PET/MR imaging. ${ }^{91}$ Also, in vivo experiments showed that ${ }^{64} \mathrm{Cu}$-labeled cRGDconjugated SPIO nanocarriers accumulated in the tumor area but not in normal tissues (Fig. 4B). Results proved that this system could be promising for both tumor targeting and as a tumor contrast agent.

5.1.2 Photoacoustic imaging (PAI). To visualize biological tissues in vivo, fluorescence and bioluminescence imaging are mostly utilized in the past few decades. However, these systems have a limitation reaching high spatial resolution and sufficient penetration depth simultaneously. ${ }^{92}$ Photoacoustic imaging (PAI), also called optoacoustic or thermoacoustic imaging, is a promising new area that has the potential to overcome this limitation.
PAI is based on the photoacoustic effect, which was first reported by Alexander Graham Bell in 1880 by the realization of sound generated by light. ${ }^{93}$ The photoacoustic effect here refers to the generation of ultrasound (acoustic) waves through the adsorption of electromagnetic energy by tissue chromophores, and these ultrasound waves produce images of tissues depending on the magnitude of the optical absorption..$^{92}$ By this technique, it is possible to achieve few centimeters depth with a scalable spatial resolution, which offers high contrast and high spatial resolution simultaneously. However, it was not until the last decade that the photoacoustic effect has developed extensively for biomedical applications such as imaging of breast, skin and the cardiovascular system. ${ }^{93}$

In an ideal PAI, the optical absorption of the desired object has to be high for better image contrast and the optical absorption of normal tissues has to be low to achieve deeper signal penetration. ${ }^{94}$ Many studies have been focused to find such contrast agents and to date these studies have reported two types of contrast agents classified as endogenous and exogenous agents. The most commonly studied endogenous agents are melanin and hemoglobin. ${ }^{95,96}$ Indocyanine green (ICG), gold nanoparticles, single wall nanotubes (SWNTs), quantum dots (QDs) and fluorescent proteins have been

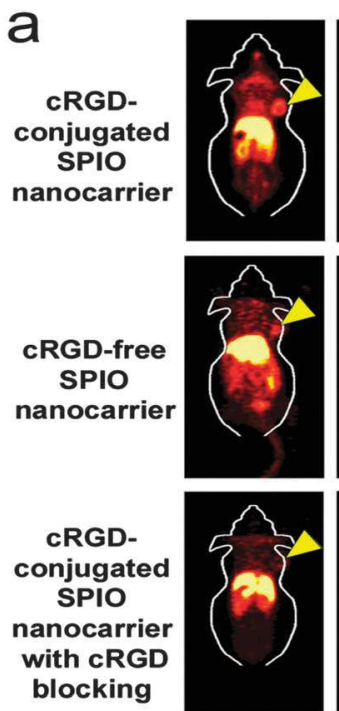

$0.5 \mathrm{~h}$

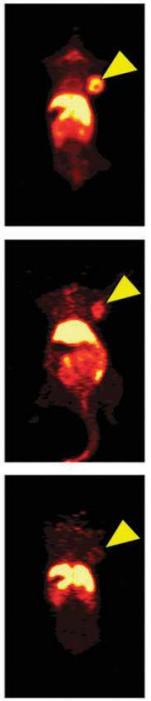

$3 \mathbf{h}$
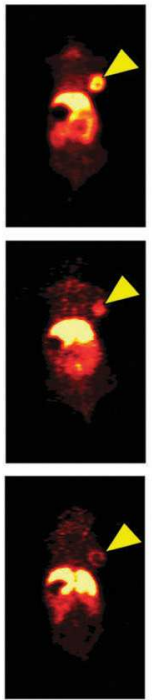

$6 \mathrm{~h}$

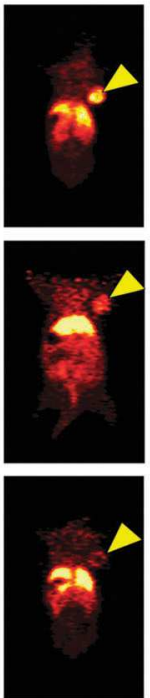

$24 \mathrm{~h}$
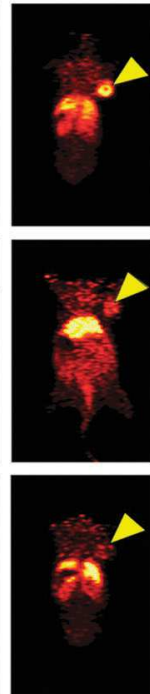

$48 \mathrm{~h}$

\section{$6 \% \mathrm{ID} / \mathrm{g}$}
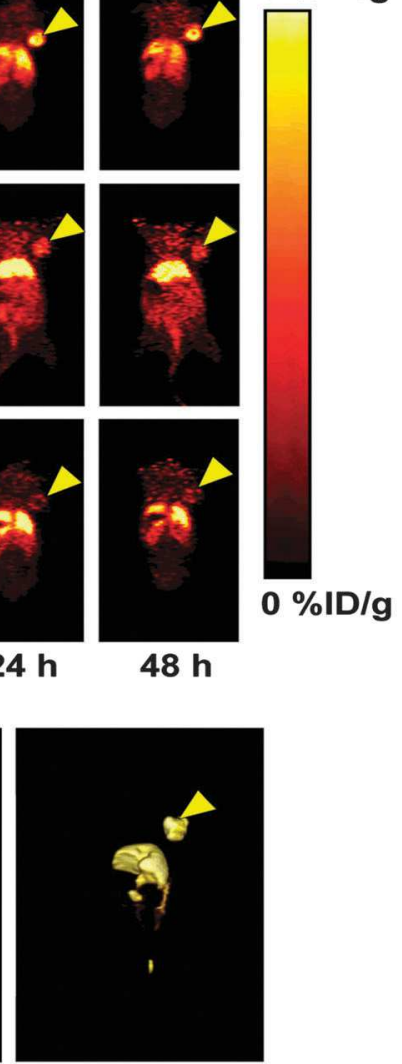

PET

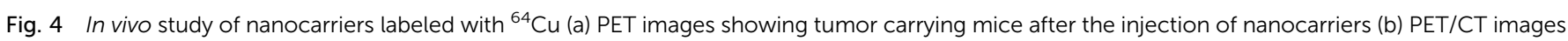

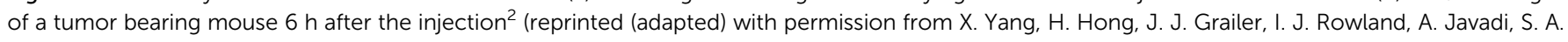
Hurley, Y. Xiao, Y. Yang, Y. Zhang, R. J. Nickles, W. Cai, D. A. Steeber and S. Gong, Biomaterials, 2011, 32, 4151-4160. Copyright (2011) Elsevier). 
reported as the most commonly used exogenous contrast agents. ${ }^{94,97-100}$

The advantages of using endogenous contrast agents for imaging purposes are that they are safe and they are able to show true physiological conditions. Even though they are sufficient enough to visualize vasculature tissues, it is not possible to visualize non-vascularized tissues with endogenous agents. ${ }^{92}$ Moreover, they are inadequate for the detection of early stage tumors. ${ }^{94}$ Therefore, exogenous contrast agents (such as gold nanoparticles) are required for better photoacoustic imaging. However, most commonly used exogenous agents have limitations in achieving effective specific targeting. ${ }^{92}$

At this point, gold-coated iron oxide nanoparticles are promising to couple photoacoustic imaging with magnetic resonance imaging and provide effective specific targeting. ${ }^{101}$ In this method, the shell thickness and surface properties of IONPs have to be controlled precisely as they determine the magnetic attraction, near-infrared (NIR) absorption, photon scattering, and further biomolecular conjugation. ${ }^{102}$

Many studies have reported direct coating of gold onto IONPs. ${ }^{103-107}$ For instance, Ji et al. reported the synthesis, characterization, and use of hybrid nanoparticles with an iron oxide core and a gold nanoshell. ${ }^{108}$ The resulting nanoparticles demonstrated superparamagnetic behavior and a significant absorbance in the near-infrared region, which is necessary for successful PAI. However, Jin et al. states that gold coating on IONPs generally produces particles that are larger than 100-200 $\mathrm{nm}$ in diameter with uneven surfaces, which negatively affects the NIR response. ${ }^{102}$ Therefore, they recently reported the synthesis of superparamagnetic iron oxide nanoparticles that are coated with a gold shell by creating a gap between the core and the shell. ${ }^{102}$ Results showed that nanoparticles have highly integrated properties, including electronic, magnetic, optical, acoustic and thermal responses. This approach produced a contrast agent that has excellent MR and PA imaging abilities and this method is named as magnetomotive photoacoustic (mmPA) imaging.

\subsection{Cell tracking}

Another application of IONPs is related to the specific cell tracking. To label and track cells in vivo, sufficient amount of magnetic nanoparticles should be loaded into the cell culture. In that case, cell tracking can be achieved with a resolution approaching the size of the cell. This can be done by conjugating cell-permeable peptides or transfection agents onto the negatively charged surface of the nanoparticles. ${ }^{23}$ To increase SPION internalization by cells, particles can be further functionalized with some specific peptides, which increase the cellular uptake, or they can be coated with dendrimers. ${ }^{109,110}$ This technology has been commonly used for stem cell tracking, and recently it has been used to track immune cells and (T) lymphocytes. ${ }^{111}$

Lu et al. reported the synthesis of IONPs with diameters of $50 \mathrm{~nm}$ that were coated with silica. To label and track human mesenchymal stem cells (hMSCs), fluorescein isothiocyanate (FITC) was conjugated to the nanoparticle surface, and labeling was achieved by clathrin and actin-dependent endocytosis with subsequent intracellular localization in late endosomes/ lysosomes. ${ }^{112}$ The results show that these bifunctionalized nanoparticles can create sufficient MRI contrast, and the labeled stem cells' viability and proliferation are not affected from the procedure. Moreover, Arbab et al. also labeled and tracked mesenchymal stem cells (MSCs), hematopoietic (CD34 ${ }^{+}$) stem cells with ferumoxides-protamine sulfate complexes. The authors tested the cellular toxicity, functional capacity, and quantitative cellular iron incorporation. ${ }^{113}$ The results showed that labeled cells did not demonstrate short or long-term toxicity, where similar cell proliferation was obtained compared to unlabeled cells.

Yeh et al. performed MRI cell tracking of rat T-cells in vivo by labeling them with superparamagnetic dextran-coated ironoxide particles. ${ }^{114}$ They induced tissue inflammation and attracted labeled T-cells by injecting calcium ionophore locally. This study was the first example of a successful specific cell tracking application in vivo through MRI. Recent studies about immune cell tracking consist of more targeted approaches with further functionalization via transfection agents. C. H. Dodd et al. tracked T-cells in vivo through labeling cells with SPIONs derivatized with a peptide sequence from transactivator protein (Tat) of HIV-1.115 MRI, FACS and biodistribution analysis showed that T-cells were efficiently loaded and tracked with these superparamagnetic agents without compromising their normal activation (Fig. 5).

\subsection{Bioseparation}

Magnetic separation is highly used in biotechnology, and it is currently the most useful application of magnetic particles. Several magnetic particle types have been developed for this purpose, but new and advanced separation techniques, which can be used in the case of dilute solutions of targeted molecules, should be investigated. ${ }^{116}$ During the last decade, SPIONs have been used for bioseparation of proteins and cells. Traditional separation techniques such as various chromatography systems and ultrafiltration are more complex and expensive than magnetic separation techniques. In addition, purification steps in the magnetic separation process with SPIONs can take place in one test tube which provides great simplicity over other procedures. ${ }^{23}$

In the magnetic separation technique, affinity ligands towards targeted compounds are immobilized on a nanoparticle surface. Then, they are mixed with the sample, containing the targeted molecule, which will be purified or separated. After an incubation time, magnetic nanoparticles bind to the target molecule specifically, subsequently they can be easily removed from the sample using a magnetic separator (Fig. 6). ${ }^{116}$ The most important advantage of this technique is that, it can be applied directly to a crude sample, and effectively separate small particles. The most commonly used affinity ligands for protein isolation are streptavidin, antibodies, protein A and G, nitrilotriacetic acid, trypsin, and trypsin inhibitor. ${ }^{11-122}$ As a magnetic separator, a small permanent magnet can be sufficient, but stronger rare-earth magnets are also commercially available. ${ }^{116}$

Fan et al. reported the synthesis of superparamagnetic $\gamma-\mathrm{Fe}_{2} \mathrm{O}_{3}$ nanoparticles via a site-exchange reaction for the 


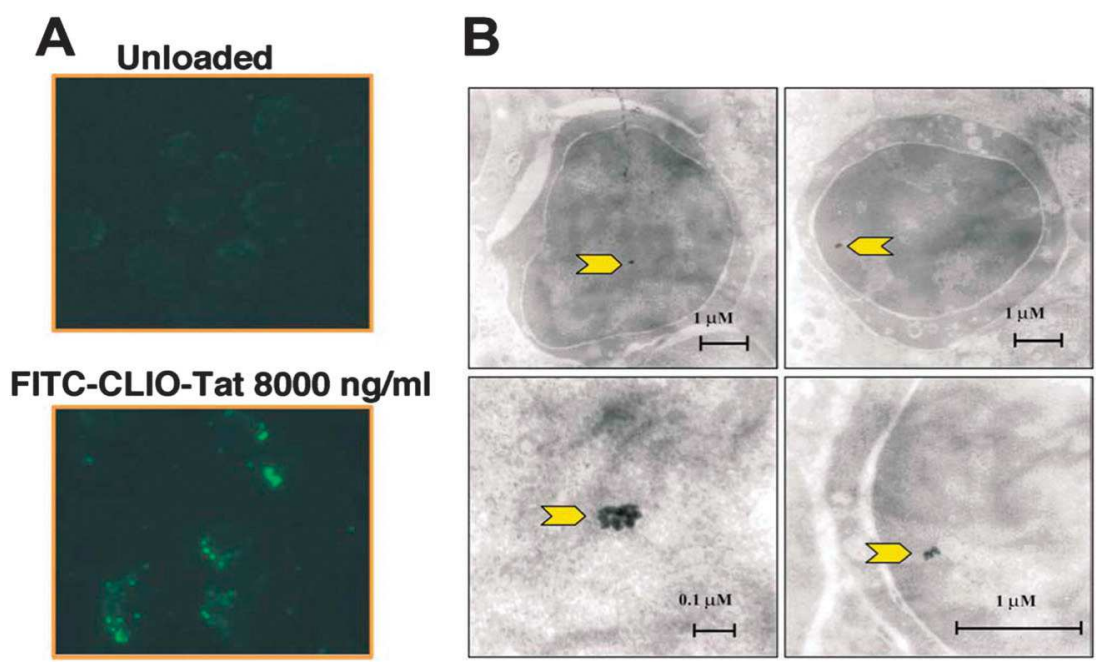

Fig. 5 Determination of Tat coated SPIONS in T cells (A) Confocal microscopy of live cells. Cytoplasm of individual cells is visible by auto fluorescence, and FITC is visible by intense green fluorescence (B) TEM analysis demonstrating the localization and clustering pattern of Tat coated SPIONs ${ }^{3}$ (reprinted (adapted) with permission from C. H. Dodd, H. C. Hsu, P. Yang, H. G. Zhang, J. D. Mountz, W. J. Chu, J. Forder, J. D. Mountz Jr, K. Zinn, J. M. Mountz, L. Josephson and R. Weissleder, J. Immunol. Methods, 2001, 256, 89-105. Copyright (2001) Elsevier).

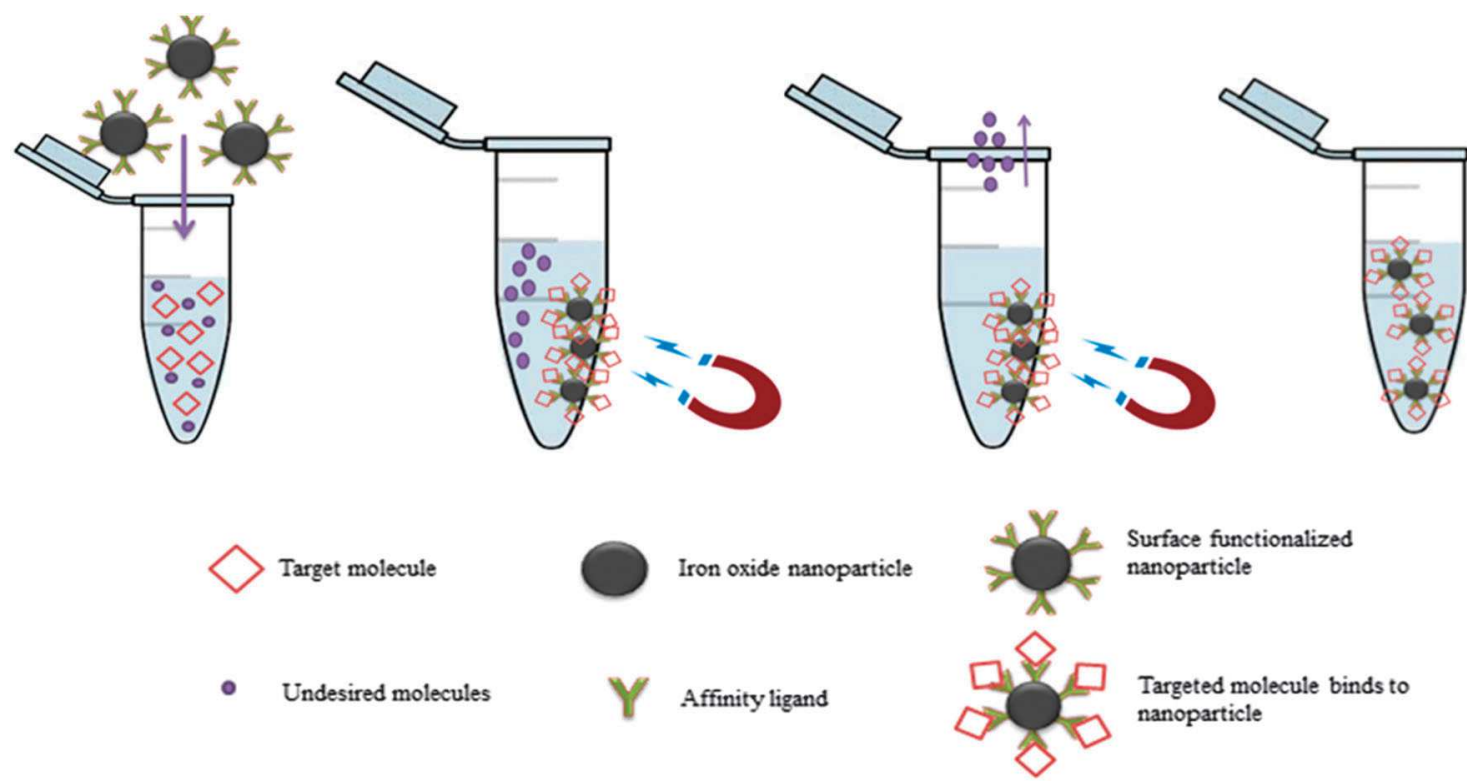

Fig. 6 Basic principle of magnetic separation.

isolation of avidin protein from its incubation solution. ${ }^{123}$ Nanoparticles were protected with oleic acid, and were further functionalized with charged bipyridinium carboxylic acids and biotin. The presence of bipyridinium significantly improved the water solubility of nanoparticles, where biotin, known for its high affinity towards avidin, was introduced onto the surface of the nanoparticles. TEM results showed that functionalized nanoparticles had a very narrow size distribution with an average core dimension of $13 \mathrm{~nm}$. Fluorescence spectra of avidin-FITC solution showed that avidin could be removed from its buffer with 96\% efficiency. ${ }^{123}$ Another example was published by Nagatani et al., wherein a new method for the transformation of cells, and selection of transformed cells by using magnetite cationic liposomes (MCLs)/DNA complex, was reported. In this study, magnetite cationic liposomes (MCLs) were associated with a plasmid vector, and then transformants were separated using a magnetic field. ${ }^{124}$

\subsection{Magnetic fluid hyperthermia}

Magnetic fluid hyperthermia (MFH) is one of the methods that are used for cancer therapy, where an alternating magnetic field to the delivered nanoparticles is applied. This magnetic field causes nanoparticles to get warmer and release heat. Therefore, tumor would be destroyed with released energy. The main function of the hyperthermia agent is to absorb the energy and convert it to a cytotoxic amount of heat, as tumor cells are 
more prone to heat compared to healthy cells. ${ }^{125}$ Hence, magnetic materials have great potential for the treatment of tumor cells, because they can be easily induced magnetically, and convert this magnetic energy to heat. Microwaves, sound waves and radio frequency can be used for magnetic induction of magnetic particles. ${ }^{126}$ Superparamagnetic nanoparticles have magnetic moment that is free to fluctuate as a response to thermal energy due their single domain ground state, and this makes them very useful for hyperthermia treatment. The use of SPIONs is promising due to both their small size and unique magnetic properties. The Curie temperature, where a material magnetization transition from permanent to induced occurs, is almost hundred degrees for SPIONs. ${ }^{127}$ However, due to biocompatibility issues, SPIONs are needed to be coated with materials such as polyethylene glycol, polyvinyl alcohol, chitosan, dextran and aminosilane. ${ }^{55,128}$

The first hyperthermia experiment with magnetic materials was done by Gilchrist et al. in 1957. In that study, 1.2 MHz magnetic field was applied to IONPs with size up to $100 \mathrm{~nm} \cdot{ }^{129-131}$ First clinical trials were done by Jordan et al., where the treatment was successful at several tumor cases. ${ }^{132}$ Specifically, the regional hyperthermia treatment was conducted clinically as a first trial on prostate cancer. ${ }^{133}$ Later, Gordon et al. used microparticles of iron oxide that were doped with yttrium for MRI combined hyperthermia treatment for liver cancer. ${ }^{131}$

In addition to MRI combined hyperthermia, drug release combined hyperthermia treatment was also considered by Hayashi et al. through the use of folic acid and beta cyclodextrin functionalized IONPs. ${ }^{134}$ The drug was incorporated into the system (Fig. 7) through beta cyclodextrin using hydrophobic interactions. When the system was heated by applying high frequency magnetic fields up to $42-45{ }^{\circ} \mathrm{C}$, the hydrophobic interaction between the drug and beta cyclodextrin was depressed, and the drug could be released. Hence, within this temperature range, both drug and hyperthermia treatments occur simultaneously. ${ }^{134}$ However, hyperthermia has some limitations. First, hyperthermia is generally preferred as a local treatment instead of a regional treatment. Another limitation is related to temperature control. The treatment is only successful at a fixed temperature range of $42-45{ }^{\circ} \mathrm{C}$ for local hyperthermia. ${ }^{129-131}$ Also, the released heat should only be applied to the targeted site rather than healthy cells. Therefore, optimizations related to the size and colloidal stability of nanoparticles are crucial for clinical success of the magnetic fluid hyperthermia therapy. ${ }^{55,130,135}$

\subsection{Gene delivery}

Gene delivery for therapeutic reasons can be achieved through viral or non-viral vectors. Viral vectors are not preferred commonly due to toxicity and severe immune response issues. Non-viral gene delivery platforms, such as needle and jet injection, hydrodynamic gene transfer, gene gun, electroporation, and sonoporation are not efficient enough to transfer the genes. ${ }^{136-140}$ Gene therapy has been mainly used for diseases caused by genetic disorder, especially for several immune system diseases; e.g. chronic granulomatus disorder, severe combined immune deficiency, and neurodegenerative diseases such as Parkinson disease, Huntington disease, and in various cancer therapies. ${ }^{141-150}$ The goal in gene delivery involves replacing or silencing the defective gene that causes the disease, where limitations are the delivery of gene to the targeted tissue or cell, and difficulty in observing the tissue response subsequently. ${ }^{151}$

Recently, magnetic nanoparticles have been considered for in vitro or in vivo gene delivery. The approach, known as magnetofection, can be used by attaching therapeutic genes onto magnetic nanoparticles, where these nanoparticles are then targeted towards specific sites via high gradient external magnets (Fig. 8). ${ }^{26,152}$ This particular system has two advantages in vivo; first, sedimentation is facilitated, and second, the specific area or tumor site can be targeted for gene delivery. Release of genes from the magnetic nanoparticles can occur either through enzymatic degradation or hydrolysis of the polymer coating around nanoparticles. ${ }^{26}$ IONPs are promising for transfection of genes at targeted sites through magnetic induction with an external magnet. ${ }^{153}$ Positively charged coating materials such as PVA, polyethylenimine (PEI) and chitosan have been generally used for coating to allow for the binding with negatively charged plasmids. ${ }^{154}$ For example, Mah et al. reported targeted delivery of DNA from magnetic nanoparticles, where adeno-associated virus (AVV), encoding green fluorescent protein (GFP), and a cleavable heparin sulfate linker have been used. ${ }^{155}$ Both in vivo and in vitro results showed that this system

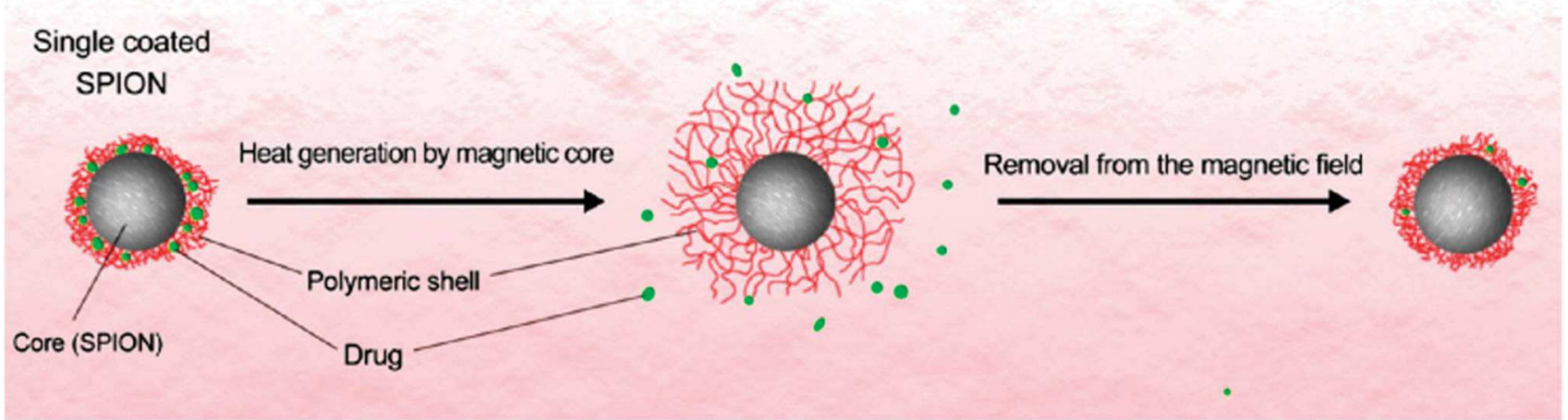

Fig. 7 Drug release combined hyperthermia treatment system ${ }^{4}$ (reprinted (adapted) with permission S. Laurent, S. Dutz, U. O. Hafeli and M. Mahmoudi, Adv. Colloid Interface Sci., 2011, 8, DOI: 10.1016/j.cis.2011.04.003. Copyright (2011) Elsevier). 


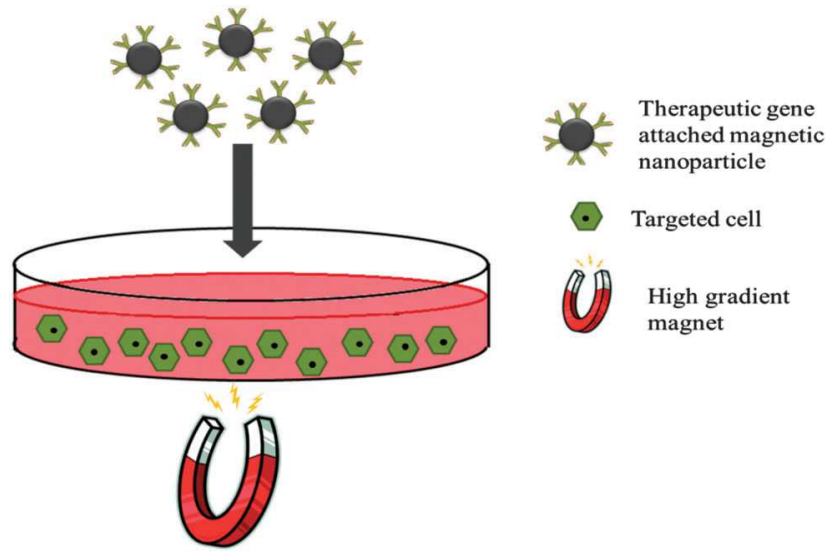

Fig. 8 Schematic representation of magnetic nanoparticle mediated gene delivery in vitro.

provides higher effective concentration of the vector, and longer exposure time of the vector to target cells.

\subsection{Drug delivery}

One of the limitations in drug delivery is the absorption of hydrophobic drugs, where the other problem involves sitespecific targeting of the drug towards the diseased site. Targeted delivery is significant for improved efficacy and biocompatibility of the drug. Hence, the design of smart delivery vehicles for the release of drugs at targeted sites, and efficient absorption of the drug by specific cells will be critical improvements in therapeutics. Nanoparticle based drug delivery is enhancing growing field due to several advantages, such as small size of the particles and strong physical properties of the nanoparticles. ${ }^{156}$ Depending on their size, nanoparticles can exhibit superparamagnetic behavior. Another crucial aspect of superparamagnetic nanoparticles is the lack of permanent magnetization. As a result of this property, nanoparticles can preserve their colloidal stability. ${ }^{157}$ However, a certain level of magnetization is required for biomedical studies, so there is a trade-off between the minimum size to prevent agglomeration and having enough magnetization to respond to the magnetic field for an application. ${ }^{157}$ Nanoparticles can easily diffuse into the peripheral tissue in the case of cancer with an enhanced permeation and retention (EPR) effect observed in mostly diseased tissues. ${ }^{157}$ Increased number of leaky vasculatures is observed in most tumor cells to increase nutrient and oxygen transport towards the tumor environment. ${ }^{158-160}$ The permeability of nanoparticles through leaky vasculatures can be utilized for the design of drug delivery vehicles. Nanoparticles can be loaded with therapeutic molecules through encapsulation, surface attachment or entrapment. ${ }^{161}$ Another advantage in the use of nanoparticles is the reduction of multidrug resistance (MDR) that occurs in hydrophobic drugs. MDR is caused by the ATP binding cassette (ABC), an over-expressed transporter in cancer cells, and causes MDR by pumping hydrophobic drugs out of cancer cells. To overcome MDR, SPIONs are used with DOX conjugation as an example. Kievit et al. showed that DOX with SPION conjugation can be used to overcome MDR, and to increase the drug delivery efficacy. ${ }^{30}$
For the delivery of magnetic nanoparticles, either magnetic force or passive targeting can be used. In passive targeting, the reticuloendothelial system (RES), a very important clearance system in the body, can be utilized. When bare nanoparticles are delivered into the body, they become vulnerable to the attachment of opsonins, plasma proteins that distinguish the non-self structures, and stick onto the surface opsonins due to their high surface tension. The attachment of nanoparticles on opsonins is mediated by nanoparticle size, shape, and agglomeration state, and surface charge. Nanoparticles larger than $250 \mathrm{~nm}$ are cleared easily from the blood stream through RES into the spleen. ${ }^{157}$ Nanoparticles within the 10-100 nm range can be cleared by liver cells, whereas nanoparticles smaller than $10 \mathrm{~nm}$ are removed through renal clearance. ${ }^{157,162,163}$ The optimal size range of nanoparticles for delivery applications has been noted as 10-100 $\mathrm{nm}$, since the blood clearance time for this size range is higher compared to other sizes. ${ }^{157}$

Active targeting includes the functionalization of nanoparticles by several targeting agents. ${ }^{164}$ This is usually a multistep process including the adhesion of coating/targeting molecules to the structure, and loading of drugs. Loading can be achieved via several ways, such as covalent conjugation or physical adsorption. ${ }^{157}$ One of the first clinical trials and release studies was investigated by Widder et al., where human serum albumin microspheres were coated with magnetite containing doxorubicin as an anticancer agent. ${ }^{165-167}$ Later, these trials continued with Lübbe et al. and Wilson et al. for the delivery of epidoxorubicin through magnetic nanoparticles. ${ }^{168,169}$

Nanoparticle stabilizers with desirable biocompatibility can be used for improved colloidal stability. Organosilane molecules with amine groups such as (3-aminopropyltriethoxysilane) APTES and APTMS have been widely used for various biological applications. ${ }^{161}$ Other compounds, such as silica derivatives, are chemically inert; however, these compounds are relatively less stable under biological conditions, and hence have not been preferred for biological applications.

There are several studies including conjugation of drugs on superparamagnetic nanoparticles, especially iron oxide nanoparticles, to have functions of both imaging and drug delivery. SPIONs that are functionalized with reversibly bound drugs can be delivered to specific sites. ${ }^{56}$ Basuki et al. reported the synthesis of $10 \mathrm{~nm}$ IONPs with excellent colloidal stability that is stabilized with functional polymers with a capability to attach DOX through a pH-responsive imine bond. ${ }^{170}$ This bond cleaves in acidic media and makes the nanoparticle system suitable for potential release in a tumor environment. Results of IONP uptake and intracellular release of DOX in 2D and 3D cell models prove that this MRI negative contrast agent can be used for both diagnosis and therapy. Mashhadizadeh et al. reported the delivery of antibiotics such as ofloxacin and ciprofloxacin from APTES coated IONPs. ${ }^{161}$ Laurent et al. developed starch derivative covered IONPs that can be functionalized with phosphate groups, and used in chemotherapy by targeting mitoxantrone to the tumor location. ${ }^{23}$ In addition, other hybrid nanoparticle designs exist, where SPIONs and quantum dots have been used to achieve targeted delivery of an anti-cancer agent, camptomicin. ${ }^{171}$ 
Recently, Kebede et al. reported the synthesis of an insulinloaded iron oxide-chitosan nanocomposite and investigated the potential of this system through oral delivery for the management of type II diabetes. ${ }^{172}$ In vivo experiments showed that the insulin loaded iron oxide-chitosan nanocomposite can lower blood glucose levels more than $51 \%$ in mild diabetic, subdiabetic, and severely diabetic rats. Similarly, Shen et al. reported the synthesis of hybrid nanogels composed from SPIONs modified by chitosan and CdTe quantum dots. ${ }^{20}$ Spherical hybrid nanogels, smaller than $160 \mathrm{~nm}$, were used for insulin loading. These hybrid nanoparticles could be promising for both cell imaging and insulin delivery purposes.

Specific targeting strategies can be used through the use of markers over expressed in cancer cells. For instance, breast cancer cells overexpress HER2 receptors, and several studies considered conjugation of anti-HER2 antibody on nanoparticles. ${ }^{157,173,174}$ Folic acid has also been used for targeting HeLa and MCF7 cells. ${ }^{175}$ Tumor endothelial cells also express cell surface receptors for angiogenesis. ${ }^{29}$ One target is $\alpha_{v} \beta_{3}$ integrin, which plays a key role in endothelial cell survival during angiogenesis. For SPION functionalization, researchers have exploited ligands such as the Arg-Gly-Asp (RGD) peptide to target $\alpha_{\mathrm{v}} \beta_{3}$ integrin on cell surface, and increase the specificity of targeting cancer cells. ${ }^{29}$ CREKA is another example that targets fibrin, found mostly around tumor areas for specific tumors. ${ }^{176,177}$

Beyond these applications, magnetic manipulation would be a choice to direct the magnetic nanoparticle conjugated drugs to the targeted site. One study representing this class is iron oxide nanoparticle conjugated paclitaxel usage to address stent limitations for adjusting drug dose. ${ }^{178}$

\subsection{Tissue repair}

To heal a particular wound in the body, tissues in the damaged site have to be joined and tissue union is generated by temperatures greater than $55{ }^{\circ} \mathrm{C} .{ }^{179}$ To heat the tissues, laser systems are currently used. However laser radiation inevitably leads to tissue necrosis in the applied area. ${ }^{180}$ To diminish the tissue damage, ways to use least harmful wavelengths and low powered lasers have to be figured out. ${ }^{11}$ The IONP usage method in tissue repairing applications is called soldering or welding. In this technique, two tissue surfaces are brought near, and then to increase the merging of the tissues, IONPs are placed in between, and required amount of heat is applied to the tissue-nanoparticle system. In tissue repairing with nanoparticles, it is desirable to use gold or silica coatings because of their strong absorbance of light. By this way, wavelengths that cause minimum harm to the tissues, and lower powered lasers can be utilized.

IONPs are recently integrated into polymeric scaffolds to provide magnetic properties and to create scaffolds with improved mechanical and biological properties for tissue repair and regeneration. For instance, Kim et al. reported the synthesis of polycaprolactone scaffolds that is merged with IONPs for bone repair. ${ }^{181}$ Results showed that these hybrid scaffolds had superparamagnetic properties and the addition of IONPs increased the mechanical stiffness, and improved the cell adhesion to the scaffold by 1.4 -fold when it was compared with the pure PCL scaffold. ${ }^{181}$ An increase in cell adhesion enables better cellular proliferation. Most importantly, cell mineralization (determined by calcium deposits quantification), which is required for bone regeneration, is significantly improved with the incorporation of IONPs.

\subsection{Manipulation of cellular organelles}

Magnetic manipulation of cellular organelles is desirable due to the applicability of the approach from a distance without any contact. ${ }^{154}$ Nanoparticles must be functionalized with specific targeting agents for specific recognition by an organelle. Manipulating cell organelles is especially attractive, as it provides information about the cell function and signaling pathways. ${ }^{154}$ Manipulation of cytoskeleton, lysosome and mitochondria through iron oxide nanoparticles has been explained in this review, as these organelles are commonly considered for targeting purposes in previous studies.

The first example of organelle manipulation via IONPs is cytoskeleton manipulation. The structure of a cell is maintained by microtubule, which is the primary component of cytoskeleton. A signaling pathway called Ran/RCC1 regulates the cell cytoskeleton. Gueroui et al. conjugated the IONPs with a regulatory protein, RanGTP, and proved that by this way the Ran/RCC1 signaling pathway can be controlled. ${ }^{182}$ Experiments are done with Xenopus laevis egg extracts, and results showed that when there was a magnetic field, orientation of the microtubule fibers was governed by the direction of this magnetic force.

Lysosome is another organelle manipulated by IONPs. When lysosome membrane permeability increases over a particular value, this leads to cell death. Therefore, this may be utilized as an effective method to kill cancer cells. Rinaldi et al. synthesized $14 \mathrm{~nm}$ IONPs coated with the proteins, which recognize the epidermal growth factor receptor (Fig. 9). ${ }^{183}$ This growth factor is highly expressed in cancer cells, so that it is used to target nanoparticles to the cancer cells in the body. IONPs coated with target proteins were rapidly internalized in the lysosomes of cancer cells. Then, an alternating magnetic field is applied, and IONPs caused heating of the lysosomes. This eventually damaged the membranes of lysosomes, increased their permeability, and engendered cell death. ${ }^{183}$

Another organelle that can be manipulated by IONPs is mitochondria. Mitochondria has very important roles in signaling, cellular differentiation, cell death and growth. ${ }^{154}$ Therefore, manipulating the mitochondria may be the key step to treat many diseases including cancer. Choi et al. used $50 \mathrm{~nm}$ magnetite form of IONPs, and coated them with cytochrome $c$-specific binding aptamers. ${ }^{184}$ When these particles were inserted in HeLa cells, they were targeted to mitochondria, and internalized rapidly. In the presence of an external static magnetic field, the viability of the cancer cells reduced significantly. ${ }^{184}$

\subsection{Other applications}

Other than the applications explained above, magnetic iron oxide nanoparticles have been used as biosensors to detect proteins, cells, nucleotides and pathogens in a biological sample. ${ }^{185-188}$ Perez et al. reported a successful detection 

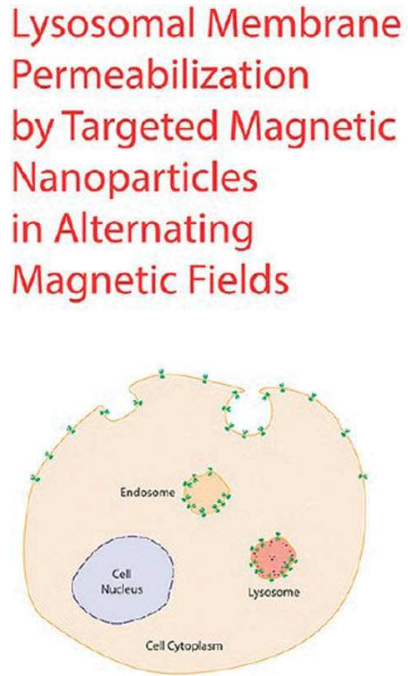

Cells with surface receptors which internalize into endosomes and lysosomes

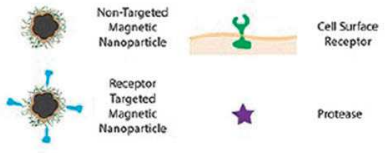

Expose Cells to Magnetic Nanoparticles

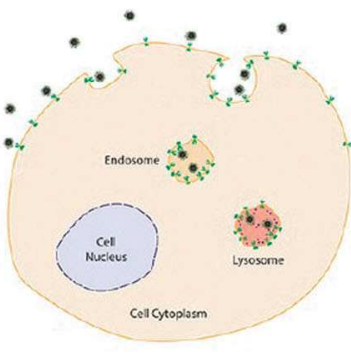

Non-specific uptake of non-targeted magnetic nanoparticles

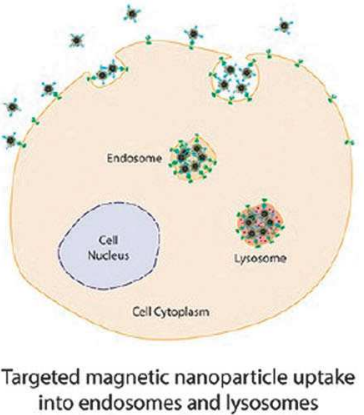

Apply

AlternatingMagnetic Field

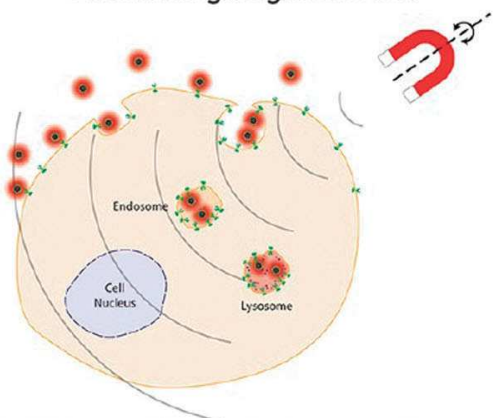

Negligible permeabilization of endosomes and lysosomes by non-targeted magnetic nanoparticles

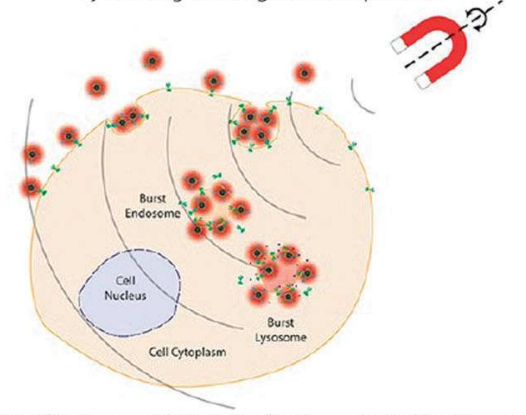

Significant permeabilization of endosomes and lysosomes by targeted magnetic nanoparticles

Fig. 9 Schematic diagram of lysosomal membrane permeabilization by IONPs ${ }^{5}$ (reprinted (adapted) with permission M. Domenech, I. Marrero-Berrios, M. Torres-Lugo and C. Rinaldi, ACS Nano, 2013, 7, 5091-5101. Copyright (2013) American Chemical Society).

technique for green fluorescent protein (GFP) by using avidin conjugated SPIONs. ${ }^{189}$ In this study, nanoparticles were first conjugated with avidin, and then the biotinylated anti-GFP polyclonal antibody was attached to the nanoparticle surfaces. Using this biosensor molecule, the authors were able to detect GFP less than 30 minutes in a dose dependent manner. ${ }^{189}$
IONPs have also been considered for manipulation of cells during the past decade. Through functionalization of nanoparticles, a specific organelle of tumor cells, progenitor cells, or stem cells can be targeted. ${ }^{154}$ It is also possible to label cells in vitro and/or in vivo with IONPs. For instance, Zharov et al. developed an in vivo approach, where circulating tumor cells

$\mathbf{A}$

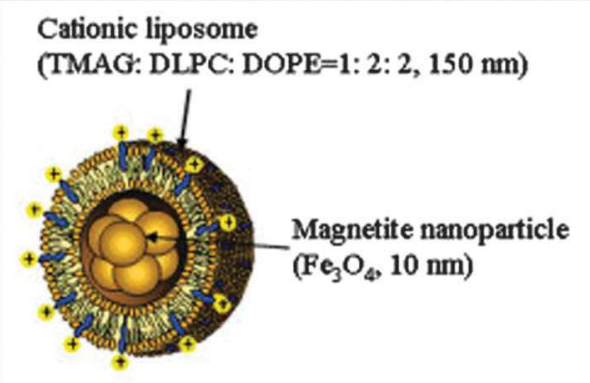

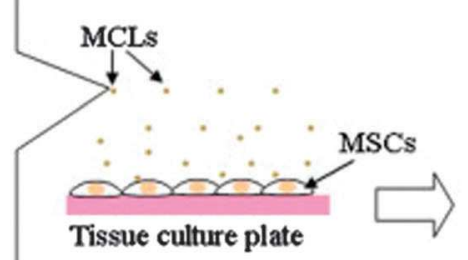

Tissue culture plate

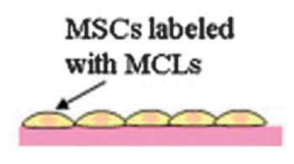
with MCLs

MSC sheet

Fig. 10 Schematic illustration of the procedure for MSC sheet construction ${ }^{6}$ (reprinted (adapted) with permission K. Shimizu, A. Ito, T. Yoshida, Y. Yamada, M. Ueda and H. Honda, J. Biomed. Mater. Res., Part B, 2007, 82, 471-480. Copyright (2007) Wiley). 
(CTCs) were captured in the bloodstream of mice. ${ }^{190}$ IONPs were functionalized with amino-terminal fragment of urokinase plasminogen activator, since this ligand specifically binds to the receptors that are highly expressed solely in cancer cells. When these particles were implanted into mice, they rapidly bound to CTCs in the bloodstream, where they could be concentrated in the blood vessel near the skin with the use of an external magnet. In a separate study by Zharov et al. a second contrast agent was used to improve detection sensitivity and specificity, where gold-plated carbon nanotubes functionalized with folic acid were chosen due to the higher photoacoustic contrast of gold compared to that of IONPs at $900 \mathrm{~nm} .{ }^{190}$

It is also possible to manipulate cells with magnetic force, after cells are labeled with IONPs. This approach is carried out in a cell culture medium, where magnetic forces have been used to levitate cells with the use of a magnet on the lid of a Petri dish to form 3D cell cultures. ${ }^{154}$ The geometry of cell population can be arranged according to the direction of the magnetic field. This principle has been used to create 3D tissue without any scaffold. ${ }^{191}$ Human mesenchymal stem cells (hMSCs) were labeled with magnetite cationic liposomes (MCLs). Next, they were implanted onto an ultra-low attachment culture surface, where a $4000 \mathrm{G}$ magnet was placed on the reverse side of the dish. After 24 hour culture period, stem cells formed multilayered sheetlike structures (Fig. 10). In vitro results demonstrated that stem cells could differentiate into osteoblasts, adipocytes, or chondrocytes. In vivo results showed that a new bone surrounded by osteoblast-like cells was formed, when after implantation of stem cells into the defective site in the crania of nude rats. ${ }^{191}$

\section{Conclusion}

In this review, we summarized the synthesis approaches, surface modifications, and applications of iron oxide nanoparticles in biotechnology and medicine. Use of IONPs in MRI, cell tracking, bioseparation, magnetic fluid hyperthermia, gene and drug delivery, tissue repair, and manipulation of cellular organelles has been discussed in detail. Even though significant improvements have been achieved with the use of IONPs, comprehensive studies are required with clinical trials and long-term toxicity studies. Future studies should also address the fate of the IONPs after in vivo implantation, such as the elimination route and retention time in specific organs.

\section{Notes and references}

1 H. Skaff, M. F. Ilker, E. B. Coughlin and T. Emrick, J. Am. Chem. Soc., 2002, 124, 5729-5733.

2 M. C. Daniel and D. Astruc, Chem. Rev., 2004, 104, 293-346.

3 J.-L. Bridot, A.-C. Faure, S. Laurent, C. Rivière, C. Billotey, B. Hiba, M. Janier, V. Josserand, J.-L. Coll, L. Vander Elst, R. Muller, S. Roux, P. Perriat and O. Tillement, J. Am. Chem. Soc., 2007, 129, 5076-5084.

$4 \mathrm{~W}$. Wu, M. Aiello, T. Zhou, A. Berliner, P. Banerjee and S. Zhou, Biomaterials, 2010, 31, 3023-3031.
5 E. Huynh and G. Zheng, Wiley Interdiscip. Rev.: Nanomed. Nanobiotechnol., 2013, 5, 250-265.

6 T. K. Jain, M. K. Reddy, M. A. Morales, D. L. Leslie-Pelecky and V. Labhasetwar, Mol. Pharmaceutics, 2008, 5, 316-327.

7 S. Naqvi, M. Samim, M. Abdin, F. J. Ahmed, A. Maitra, C. Prashant and A. K. Dinda, Int. J. Nanomed., 2010, 5, 983-989.

8 A. Petri-Fink, B. Steitz, A. Finka, J. Salaklang and H. Hofmann, Eur. J. Pharm. Biopharm., 2008, 68, 129-137.

9 W. H. Binder and H. C. Weinstabl, Monatsh. Chem., 2007, 138, 315-320.

10 M. Mahmoudi, A. Simchi and M. Imani, J. Iran. Chem. Soc., 2010, 7, S1-S27.

11 A. K. Gupta and M. Gupta, Biomaterials, 2005, 26, 3995-4021.

12 S. Sun, H. Zeng, D. B. Robinson, S. Raoux, P. M. Rice, S. X. Wang and G. Li, J. Am. Chem. Soc., 2004, 126, 273-279.

13 J. W. M. Bulte, M. d. Cuyper, D. Despres and J. A. Frank, J. Magn. Magn. Mater., 1999, 194, 204-209.

14 Y. Zhang, N. Kohler and M. Zhang, Biomaterials, 2002, 23, 1553-1561.

15 Z. Cui, C.-H. Hsu and R. J. Mumper, Drug Dev. Ind. Pharm., 2003, 29, 689-700.

16 A. K. Gupta and A. S. G. Curtis, Biomaterials, 2004, 25, 3029-3040.

17 D. K. Kim, M. Mikhaylova, F. H. Wang, J. Kehr, B. Bjelke, Y. Zhang, T. Tsakalakos and M. Muhammed, Chem. Mater., 2003, 15, 4343-4351.

18 H. Lee, E. Lee, D. K. Kim, N. K. Jang, Y. Y. Jeong and S. Jon, J. Am. Chem. Soc., 2006, 128, 7383-7389.

19 C. W. Lin, S. J. Tseng, I. M. Kempson, S. C. Yang, T. M. Hong and P. C. Yang, Biomaterials, 2013, 34, 4387-4393.

20 J.-M. Shen, L. Xu, Y. Lu, H.-M. Cao, Z.-G. Xu, T. Chen and H.-X. Zhang, Int. J. Pharm., 2012, 427, 400-409.

21 C. Boyer, M. R. Whittaker, V. Bulmus, J. Liu and T. P. Davis, NPG Asia Mater., 2010, 2, 23-30.

22 S.-J. Cho, B. R. Jarrett, A. Y. Louie and S. M. Kauzlarich, Nanotechnology, 2006, 17, 640-644.

23 S. Laurent, D. Forge, M. Port, A. Roch, C. Robic, L. Vander Elst and R. N. Muller, Chem. Rev., 2008, 108, 2064-2110.

24 D. P. Cormode, B. L. Sanchez-Gaytan, A. J. Mieszawska, Z. A. Fayad and W. J. M. Mulder, NMR Biomed., 2013, 26, 766-780.

25 F. Sonvico, S. Mornet, S. Vasseur, C. Dubernet, D. Jaillard, J. Degrouard, J. Hoebeke, E. Duguet, P. Colombo and P. Couvreur, Bioconjugate Chem., 2005, 16, 1181-1188.

26 J. Dobson, Gene Ther., 2006, 13, 283-287.

27 P. Jendelová, V. Herynek, L. Urdzíková, K. Glogarová, J. Kroupová, B. Andersson, V. Bryja, M. Burian, M. Hájek and E. Syková, J. Neurosci. Res., 2004, 76, 232-243.

28 C. C. Berry, J. Phys. D: Appl. Phys., 2009, 42, 1-9.

29 N. Nasongkla, X. Shuai, H. Ai, B. D. Weinberg, J. Pink, D. A. Boothman and J. Gao, Angew. Chem., Int. Ed., 2004, 43, 6323-6327.

30 F. M. Kievit, F. Y. Wang, C. Fang, H. Mok, K. Wang, J. R. Silber, R. G. Ellenbogen and M. Zhang, J. Controlled Release, 2011, 152, 76-83. 
31 C. Nazli, G. S. Demirer, Y. Yar, H. Y. Acar and S. Kizilel, Colloids Surf., B, 2014, 122, 674-683.

32 K. A. Kelly, J. R. Allport, A. Tsourkas, V. R. Shinde-Patil, L. Josephson and R. Weissleder, Circ. Res., 2005, 96, 327-336.

33 P. Reimer, R. Weissleder, T. Shen, W. T. Knoefel and T. J. Brady, Radiology, 1994, 193, 527-531.

34 A. M. G. C. Dias, A. Hussain, A. S. Marcos and A. C. A. Roque, Biotechnol. Adv., 2011, 29, 142-155.

35 S. Benedetto, R. Pulito, S. G. Crich, G. Tarone, S. Aime, L. Silengo and J. Hamm, Magn. Reson. Med., 2006, 56, 711-716.

36 J. R. McCarthy and R. Weissleder, Adv. Drug Delivery Rev., 2008, 60, 1241-1251.

37 J. S. Basuki, L. Esser, H. T. T. Duong, Q. Zhang, P. Wilson, M. R. Whittaker, D. M. Haddleton, C. Boyer and T. P. Davis, Chem. Sci., 2014, 5, 715-726.

38 C. Pascal, J. L. Pascal, F. Favier, M. L. Elidrissi Moubtassim and C. Payen, Chem. Mater., 1998, 11, 141-147.

39 K. V. P. M. Shafi, A. Ulman, X. Yan, N.-L. Yang, C. Estournès, H. White and M. Rafailovich, Langmuir, 2001, 17, 5093-5097.

40 Y. Lu, Y. Yin, B. T. Mayers and Y. Xia, Nano Lett., 2002, 2, 183-186.

41 M. Carmen Bautista, O. Bomati-Miguel, M. del Puerto Morales, C. J. Serna and S. Veintemillas-Verdaguer, J. Magn. Magn. Mater., 2005, 293, 20-27.

42 C. E. Sjøgren, K. Briley-Sæbø, M. Hanson and C. Johansson, Magn. Reson. Med., 1994, 31, 268-272.

43 W. Jiang, H. C. Yang, S. Y. Yang, H. E. Horng, J. C. Hung, Y. C. Chen and C.-Y. Hong, J. Magn. Magn. Mater., 2004, 283, 210-214.

44 A. K. Gupta and S. Wells, IEEE Trans. Nanobioscience, 2004, 3, 66-73.

45 J. Vidal-Vidal, M. A. López-Quintela and J. Rivas, Colloids Surf., A, 2006, 288, 44-51.

46 H. Zhang and G. Zhu, Appl. Surf. Sci., 2012, 258, 4952-4959.

47 S. Ge, X. Shi, K. Sun, C. Li, C. Uher, J. R. Baker, M. M. Banaszak Holl and B. G. Orr, J. Phys. Chem. C, 2009, 113, 13593-13599.

48 Y.-h. Zheng, Y. Cheng, F. Bao and Y.-s. Wang, Mater. Res. Bull., 2006, 41, 525-529.

49 Y. B. Khollam, S. R. Dhage, H. S. Potdar, S. B. Deshpande, P. P. Bakare, S. D. Kulkarni and S. K. Date, Mater. Lett., 2002, 56, 571-577.

50 R. Y. Hong, J. H. Li, H. Z. Li, J. Ding, Y. Zheng and D. G. Wei, J. Magn. Magn. Mater., 2008, 320, 1605-1614.

51 T. Hyeon, S. S. Lee, J. Park, Y. Chung and H. B. Na, J. Am. Chem. Soc., 2001, 123, 12798-12801.

52 P. Tartaj, M. D. Morales, S. Veintemillas-Verdaguer, T. Gonzalez-Carreno and C. J. Serna, J. Phys. D: Appl. Phys., 2003, 36, R182-R197.

53 D. Ling and T. Hyeon, Small, 2013, 9, 1450-1466.

54 C. Nazli, T. I. Ergenc, Y. Yar, H. Y. Acar and S. Kizilel, Int. J. Nanomed., 2012, 7, 1903-1920.

55 M. Mahmoudi, S. Sant, B. Wang, S. Laurent and T. Sen, Adv. Drug Delivery Rev., 2011, 63, 24-46.
56 T. Neuberger, B. Schöpf, H. Hofmann, M. Hofmann and B. von Rechenberg, J. Magn. Magn. Mater., 2005, 293, 483-496.

57 G. Kataby, A. Ulman, R. Prozorov and A. Gedanken, Langmuir, 1998, 14, 1512-1515.

58 M. Anbarasu, M. Anandan, E. Chinnasamy, V. Gopinath and K. Balamurugan, Spectrochim. Acta, Part A, 2015, 135, 536-539.

59 A. Masoudi, H. R. Madaah Hosseini, M. A. Shokrgozar, R. Ahmadi and M. A. Oghabian, Int. J. Pharm., 2012, 433, 129-141.

60 H. Zhang, Q. Wang and L. Li, Polym. Int., 2008, 97-104, DOI: $10.1002 /$ pi.2498.

61 M. Rahman, S. Afrin and P. Haque, Prog. Biomater., 2014, 3, 1-9.

62 H. Pardoe, W. Chua-Anusorn, T. G. S. Pierre and J. Dobson, J. Magn. Magn. Mater., 2001, 225, 41-46.

63 M. Mahmoudi, A. Simchi, M. Imani, M. A. Shokrgozar, A. S. Milani, U. O. Häfeli and P. Stroeve, Colloids Surf., B, 2010, 75, 300-309.

64 S. Kayal and R. V. Ramanujan, Mater. Sci. Eng., C, 2010, 30, 484-490.

65 M. E. Khosroshahi and L. Ghazanfari, J. Magn. Magn. Mater., 2012, 324, 4143-4146.

66 S. A. Agnihotri, N. N. Mallikarjuna and T. M. Aminabhavi, J. Controlled Release, 2004, 100, 5-28.

67 V. I. Shubayev, T. R. Pisanic, 2nd and S. Jin, Adv. Drug Delivery Rev., 2009, 61, 467-477.

68 J. Castelló, M. Gallardo, M. A. Busquets and J. Estelrich, Colloids Surf., A, 2015, 468, 151-158.

69 H. Shagholani, S. M. Ghoreishi and M. Mousazadeh, Int. J. Biol. Macromol., 2015, 78, 130-136.

70 X. M. Zhu, Y. X. Wang, K. C. Leung, S. F. Lee, F. Zhao, D. W. Wang, J. M. Lai, C. Wan, C. H. Cheng and A. T. Ahuja, Int. J. Nanomed., 2012, 7, 953-964.

71 L. Du, J. Chen, Y. Qi, D. Li, C. Yuan, M. C. Lin, D. T. Yew, H. F. Kung, J. C. Yu and L. Lai, Int. J. Nanomed., 2007, 2, 805-812.

72 L. Josephson, C.-H. Tung, A. Moore and R. Weissleder, Bioconjugate Chem., 1999, 10, 186-191.

73 A. Jafari, M. Salouti, S. F. Shayesteh, Z. Heidari, A. B. Rajabi, K. Boustani and A. Nahardani, Nanotechnology, 2015, 26, 075101.

74 W. Wu, Q. He and C. Jiang, Nanoscale Res. Lett., 2008, 3, 397-415.

75 S. A. Corr, Y. P. Rakovich and Y. K. Gun'ko, Nanoscale Res. Lett., 2008, 3, 87-104.

76 H. L. Ding, Y. X. Zhang, S. Wang, J. M. Xu, S. C. Xu and G. H. Li, Chem. Mater., 2012, 24, 4572-4580.

77 S. Santra, R. Tapec, N. Theodoropoulou, J. Dobson, A. Hebard and W. Tan, Langmuir, 2001, 17, 2900-2906.

78 J. Lin, W. L. Zhou, A. Kumbhar, J. Wiemann, J. Y. Fang, E. E. Carpenter and C. J. O'Connor, J. Solid State Chem., 2001, 159, 26-31.

79 G. Liang, S. Cai, P. Zhang, Y. Peng, H. Chen, S. Zhang and J. Kong, Anal. Chim. Acta, 2011, 689, 243-249. 
80 F. Mohammad, G. Balaji, A. Weber, R. M. Uppu and C. S. S. R. Kumar, J. Phys. Chem. C, 2010, 114, 19194-19201.

81 J. S. Basuki, L. Esser, P. B. Zetterlund, M. R. Whittaker, C. Boyer and T. P. Davis, Macromolecules, 2013, 46, 6038-6047.

82 L. X. Tiefenauer, A. Tschirky, G. Kühne and R. Y. Andres, Magn. Reson. Imaging, 1996, 14, 391-402.

83 B. Gustafsson, S. Youens and A. Y. Louie, Bioconjugate Chem., 2006, 17, 538-547.

84 C. Lemarchand, R. Gref and P. Couvreur, Eur. J. Pharm. Biopharm., 2004, 58, 327-341.

85 T. Atanasijevic, M. Shusteff, P. Fam and A. Jasanoff, Proc. Natl. Acad. Sci. U. S. A., 2006, 103, 14707-14712.

86 J. S. Basuki, A. Jacquemin, L. Esser, Y. Li, C. Boyer and T. P. Davis, Polym. Chem., 2014, 5, 2611-2620.

87 J. Bremerich, D. Bilecen and P. Reimer, Eur. J. Radiol., 2007, 17, 3017-3024.

88 A. Ito, M. Shinkai, H. Honda and T. Kobayashi, J. Biosci. Bioeng., 2005, 100, 1-11.

89 S. Boutry, S. Laurent, L. V. Elst and R. N. Muller, Contrast Media Mol. Imaging, 2006, 1, 15-22.

90 M. K. Yu, J. Park, S. Park, S. Jon, Y. Y. Jeong, J. W. Kim, J. J. Min and K. Kim, Angew. Chem., Int. Ed., 2008, 47, 5362-5365.

91 X. Yang, H. Hong, J. J. Grailer, I. J. Rowland, A. Javadi, S. A. Hurley, Y. Xiao, Y. Yang, Y. Zhang, R. J. Nickles, W. Cai, D. A. Steeber and S. Gong, Biomaterials, 2011, 32, 4151-4160.

92 A. P. Jathoul, J. Laufer, O. Ogunlade, B. Treeby, B. Cox, E. Zhang, P. Johnson, A. R. Pizzey, B. Philip, T. Marafioti, M. F. Lythgoe, R. B. Pedley, M. A. Pule and P. Beard, Nat. Photonics, 2015, DOI: 10.1038/nphoton.2015.22.

93 M. Xu and L. V. Wang, Rev. Sci. Instrum., 2006, 77, 041101.

94 Y. Zhang, H. Hong and W. Cai, Cold Spring Harb. Protoc., 2011, 2011, pdb top065508.

95 X. Wang, Y. Pang, G. Ku, G. Stoica and L. V. Wang, Opt. Lett., 2003, 28, 1739-1741.

96 J.-T. Oh, M.-L. Li, H. F. Zhang, K. Maslov, G. Stoica and L. V. Wang, J. Biomed. Opt., 2006, 11, 034032.

97 G. Ku and L. V. Wang, Opt. Lett., 2005, 30, 507-509.

98 W. Cai, T. Gao, H. Hong and J. Sun, Nanotechnol., Sci. Appl., 2008, 1, 17.

99 A. De La Zerda, C. Zavaleta, S. Keren, S. Vaithilingam, S. Bodapati, Z. Liu, J. Levi, B. R. Smith, T.-J. Ma and O. Oralkan, Nat. Nanotechnol., 2008, 3, 557-562.

100 E. V. Shashkov, M. Everts, E. I. Galanzha and V. P. Zharov, Nano Lett., 2008, 8, 3953-3958.

101 G. P. Luke, D. Yeager and S. Y. Emelianov, Ann. Biomed. Eng., 2012, 40, 422-437.

102 Y. Jin, C. Jia, S. W. Huang, M. O’Donnell and X. Gao, Nat. Commun., 2010, 1, 41.

103 I. Y. Goon, L. M. H. Lai, M. Lim, P. Munroe, J. J. Gooding and R. Amal, Chem. Mater., 2009, 21, 673-681.

104 S.-J. Cho, J.-C. Idrobo, J. Olamit, K. Liu, N. D. Browning and S. M. Kauzlarich, Chem. Mater., 2005, 17, 3181-3186.

105 J. L. Lyon, D. A. Fleming, M. B. Stone, P. Schiffer and M. E. Williams, Nano Lett., 2004, 4, 719-723.
106 Z. Xu, Y. Hou and S. Sun, J. Am. Chem. Soc., 2007, 129, 8698-8699.

107 L. Wang, L. Wang, J. Luo, Q. Fan, M. Suzuki, I. S. Suzuki, M. H. Engelhard, Y. Lin, N. Kim and J. Q. Wang, J. Phys. Chem. B, 2005, 109, 21593-21601.

108 X. Ji, R. Shao, A. M. Elliott, R. J. Stafford, E. Esparza-Coss, J. A. Bankson, G. Liang, Z.-P. Luo, K. Park and J. T. Markert, J. Phys. Chem. C, 2007, 111, 6245-6251.

109 M. Zhao, M. F. Kircher, L. Josephson and R. Weissleder, Bioconjugate Chem., 2002, 13, 840-844.

110 E. Strable, K. Vivekanandan, M. Allen, T. Douglas, J. W. M. Bulte and B. Moskowitz, Chem. Mater., 2001, 13, 2201-2209.

111 J. W. M. Bulte and D. L. Kraitchman, NMR Biomed., 2004, 17, 484-499.

112 C. W. Lu, T. H. Chung, Y. C. Chen, Y. Hung, Y. S. Lin, S. H. Wu, C. Y. Mou, J. K. Hsiao, H. M. Liu, M. Yao, S. C. Hsu, C. S. Yang and D. M. Huang, Nano Lett., 2007, 7, 149-154.

113 A. S. Arbab, J. A. Frank, G. T. Yocum, H. Kalish, E. K. Jordan, S. A. Anderson, A. Y. Khakoo and E. J. Read, Blood, 2004, 104, 1217-1223.

114 T.-C. Yeh, W. Zhang, S. T. Ildstad and C. Ho, Magn. Reson. Med., 1995, 33, 200-208.

115 C. H. Dodd, H. C. Hsu, P. Yang, H. G. Zhang, J. D. Mountz, W. J. Chu, J. Forder, J. D. Mountz Jr, K. Zinn, J. M. Mountz, L. Josephson and R. Weissleder, J. Immunol. Methods, 2001, 256, 89-105.

116 I. Safarik and M. Safarikova, Biomagn. Res. Technol., 2004, 2, 7-17.

117 S. Girault, G. Chassaing, J. C. Blais, A. Brunot and G. Bolbach, Anal. Chem., 1996, 68, 2122-2126.

118 Y.-S. Yang, M.-C. W. Yang, B. Wang and J. C. Weissler, Am. J. Respir. Cell Mol. Biol., 2001, 24, 30-37.

119 M. N. Widjojoatmodjo, A. C. Fluit, R. Torensma and J. Verhoef, J. Immunol. Methods, 1993, 165, 11-19.

120 Z. Ji, D. I. Pinon and L. J. Miller, Anal. Biochem., 1996, 240, 197-201.

121 X. An, Z. Su and H. Zeng, J. Chem. Technol. Biotechnol., 2003, 78, 596-600.

122 H. P. Khng, D. Cunliffe, S. Davies, N. A. Turner and E. N. Vulfson, Biotechnol. Bioeng., 1998, 60, 419-424.

123 J. Fan, J. Lu, R. Xu, R. Jiang and Y. Gao, J. Colloid Interface Sci., 2003, 266, 215-218.

124 N. Nagatani, M. Shinkai, H. Honda and T. Kobayashi, Biotechnol. Tech., 1998, 12, 525-528.

125 P. Cherukuri, E. S. Glazer and S. A. Curley, Adv. Drug Delivery Rev., 2010, 62, 339-345.

126 D. K. Chatterjee, P. Diagaradjane and S. Krishnan, Ther. Delivery, 2011, 2, 1001-1014.

127 S. Laurent, S. Dutz, U. O. Hafeli and M. Mahmoudi, Adv. Colloid Interface Sci., 2011, 166, 8-23.

128 A. C. Silva, T. R. Oliveira, J. B. Mamani, S. M. Malheiros, L. Malavolta, L. F. Pavon, T. T. Sibov, E. Amaro, Jr., A. Tannus, E. L. Vidoto, M. J. Martins, R. S. Santos and L. F. Gamarra, Int. J. Nanomed., 2011, 6, 591-603. 
129 M. Johannsen, B. Thiesen, A. Jordan and P. Wust, Int. J. Hyperthermia, 2010, 26, 790-795.

130 S. Laurent, S. Dutz, U. O. Hafeli and M. Mahmoudi, Adv. Colloid Interface Sci., 2011, 8, DOI: 10.1016/j.cis.2011.04.003.

131 A. C. Gordon, R. J. Lewandowski, R. Salem, A. C. Larson, D. E. Day and R. A. Omary, J. Vasc. Interv. Radiol., 2014, 25, 397-404.

132 S. Laurent and M. Mahmoudi, Int. J. Mol. Epidemiol. Genet., 2011, 2, 367-390.

133 M. Johannsen, U. Gneveckow, L. Eckelt, A. Feussner, N. WaldÖFner, R. Scholz, S. Deger, P. Wust, S. A. Loening and A. Jordan, Int. J. Hyperthermia, 2005, 21, 637-647.

134 K. Hayashi, K. Ono, H. Suzuki, M. Sawada, M. Moriya, W. Sakamoto and T. Yogo, ACS Appl. Mater. Interfaces, 2010, 2, 1903-1911.

135 R. Hergt and S. Dutz, J. Magn. Magn. Mater., 2007, 311, 187-192.

136 W. Walther, R. Siegel, D. Kobelt, T. Knosel, M. Dietel, A. Bembenek, J. Aumann, M. Schleef, R. Baier, U. Stein and P. M. Schlag, Clin. Cancer Res., 2008, 14, 7545-7553.

137 T. Suda, K. Suda and D. Liu, Mol. Ther., 2008, 16, 1098-1104.

138 K. S. Goudy, B. Wang and R. Tisch, Clin. Immunol., 2008, 129, 49-57.

139 G. Marti, M. Ferguson, J. Wang, C. Byrnes, R. Dieb, R. Qaiser, P. Bonde, M. D. Duncan and J. W. Harmon, Gene Ther., 2004, 11, 1780-1785.

140 S. Tsunoda, O. Mazda, Y. Oda, Y. Iida, S. Akabame, T. Kishida, M. Shin-Ya, H. Asada, S. Gojo, J. Imanishi, H. Matsubara and T. Yoshikawa, Biochem. Biophys. Res. Commun., 2005, 336, 118-127.

141 M. C. Dinauer, M. A. Gifford, N. Pech, L. L. Li and P. Emshwiller, Blood, 2001, 97, 3738-3745.

142 Y. Gelfand and M. G. Kaplitt, World Neurosurg., 2013, 80, S32.e11-e38.

143 S. Muramatsu, Clin. Neurol., 2012, 52, 896-898.

144 Y. Nakata, T. Yasuda and H. Mochizuki, Curr. Mol. Med., 2012, 12, 1311-1318.

145 R. L. Rodnitzky, Parkinson's Dis. Relat. Disord., 2012, 18(suppl), S37-S40.

146 A. Drinkut, Y. Tereshchenko, J. B. Schulz, M. Bahr and S. Kugler, Mol. Ther., 2012, 20, 534-543.

147 E. Cederfjall, G. Sahin and D. Kirik, Neurobiol. Dis., 2012, 48, 222-227.

148 H. A. Popiel, T. Takeuchi, H. Fujita, K. Yamamoto, C. Ito, H. Yamane, S. Muramatsu, T. Toda, K. Wada and Y. Nagai, PLoS One, 2012, 7, e51069.

149 S. Ramaswamy and J. H. Kordower, Neurobiol. Dis., 2012, 48, 243-254.

150 S. Prijic, L. Prosen, M. Cemazar, J. Scancar, R. Romih, J. Lavrencak, V. B. Bregar, A. Coer, M. Krzan, A. Znidarsic and G. Sersa, Biomaterials, 2012, 33, 4379-4391.

151 R. Huschka, A. Barhoumi, Q. Liu, J. A. Roth, L. Ji and N. J. Halas, ACS Nano, 2012, 6, 7681-7691.

152 C. Plank, U. Schillinger, F. Scherer, C. Bergemann, J. S. Remy, F. Krotz, M. Anton, J. Lausier and J. Rosenecker, Biol. Chem., 2003, 384, 737-747.
153 C. Boyer, P. Priyanto, T. P. Davis, D. Pissuwan, V. Bulmus, M. Kavallaris, W. Y. Teoh, R. Amal, M. Carroll and R. Woodward, J. Mater. Chem., 2010, 20, 255-265.

154 Y. Liu, Y. Gao and C. Xu, Chin. Phys. B, 2013, 22, 097503.

155 C. Mah, T. J. Fraites Jr, I. Zolotukhin, T. R. Flotte, B. J. Byrne, S. Song, J. Dobson and C. Batich, Mol. Ther., 2002, 6, 106-112.

156 G. Orive, R. M. Hernández, A. R. Gascón, J. L. Pedraz and A. Domínguez-Gil, Curr. Opin. Biotechnol., 2003, 14, 659-664.

157 M. Colombo, S. Carregal-Romero, M. F. Casula, L. Gutierrez, M. P. Morales, I. B. Bohm, J. T. Heverhagen, D. Prosperi and W. J. Parak, Chem. Soc. Rev., 2012, 41, 4306-4334.

158 I. K. Kwon, S. C. Lee, B. Han and K. Park, J. Controlled Release, 2012, 164, 108-114.

159 K. S. Oh, H. Lee, J. Y. Kim, E. J. Koo, E. H. Lee, J. H. Park, S. Y. Kim, K. Kim, I. C. Kwon and S. H. Yuk, J. Controlled Release, 2013, 165, 9-15.

160 M. R. Saboktakin, R. M. Tabatabaie, P. Ostovarazar, A. Maharramov and M. A. Ramazanov, Int. J. Biol. Macromol., 2012, 51, 544-549.

161 M. H. Mashhadizadeh, J. Nanomed. Nanotechnol., 2012, 3, 251-258.

162 J. Chomoucka, J. Drbohlavova, D. Huska, V. Adam, R. Kizek and J. Hubalek, Pharmacol. Res., 2010, 62, 144-149.

163 H. S. Choi, F. Liu, K. Nasr, P. Misra, J. V. Frangioni, W. Liu and M. G. Bawendi, Nat. Nanotechnol., 2010, 5, 42-47.

164 T. T. T. N'Guyen, H. T. T. Duong, J. Basuki, V. Montembault, S. Pascual, C. Guibert, J. Fresnais, C. Boyer, M. R. Whittaker and T. P. Davis, Angew. Chem., 2013, 125, 14402-14406.

165 K. Widder, G. Flouret and A. Senyei, J. Pharm. Sci., 1979, 68, 79-82.

166 K. J. Widder, A. E. Senyei and D. F. Ranney, in $A d v$. Pharmacol., ed. A. G. F. H. I. J. K. Silvio Garattini and R. J. Schnitzer, Academic Press, 1979, vol. 16, pp. 213-271.

167 S. C. McBain, H. H. P. Yiu and J. Dobson, Int. J. Nanomed., 2008, 3, 169-180.

168 A. S. Lübbe, C. Bergemann, H. Riess, F. Schriever, W. Huhnt, D. Huhn, N. Haas, B. Sander, A. J. Lemke, D. Ohlendorf, P. Reichardt, B. Dörken, F. Herrmann, R. Gürtler, P. Hohenberger, K. Possinger, M. Matthias and R. Sohr, Cancer Res., 1996, 56, 4686-4693.

169 M. W. Wilson, R. K. Kerlan Jr, N. A. Fidelman, J. M. LaBerge, R. L. Gordon, A. P. Venook and J. Koda, Radiology, 2004, 230, 287-293.

170 J. S. Basuki, H. T. T. Duong, A. Macmillan, R. B. Erlich, L. Esser, M. C. Akerfeldt, R. M. Whan, M. Kavallaris, C. Boyer and T. P. Davis, ACS Nano, 2013, 7, 10175-10189.

171 J. M. Shen, X. M. Guan, X. Y. Liu, J. F. Lan, T. Cheng and H. X. Zhang, Bioconjugate Chem., 2012, 23, 1010-1021.

172 A. Kebede, A. V. Gholap, A. K. Singh, N. K. Giri, A. K. Rai, P. K. Rai and G. Watal, J. Lasers Med. Sci., 2013, 28, 579-587.

173 M. K. Yu, I. H. Lee, J. S. So, S. Jon, D. Kim and Y. Y. Jeong, Small, 2011, 7, 2241-2249. 
174 H. Chen, L. Wang, Q. Yu, D. Tiwari, J. Huang, H. Mao, W. Qian, L. Yang, H. Yi and A. Y. Wang, Int. J. Nanomed., 2013, 8, 3781-3794.

175 F. H. Chen, L. M. Zhang, Q. T. Chen, Y. Zhang and Z. J. Zhang, Chem. Commun., 2010, 46, 8633-8635.

176 E. J. Chung, K. Nord, M. V. Tirrell, Y. Cheng, R. Morshed, Y. Han, M. L. Wegscheid, B. Auffinger, D. A. Wainwright and M. S. Lesniak, Biomaterials, 2014, 35, 1249-1256.

177 A. M. Kruse, K. W. Anderson, J. Z. Hilt and S. A. Meenach, Acta Biomater., 2014, 10, 2622-2629.

178 M. Chorny, I. Fishbein, B. B. Yellen, I. S. Alferiev, M. Bakay, S. Ganta, R. Adamo, M. Amiji, G. Friedman, R. J. Levy and A. M. Klibanov, Proc. Natl. Acad. Sci. U. S. A., 2010, 8346, DOI: 10.1073/pnas.0909506107.

179 B. Lobel, O. Eyal, N. Kariv and A. Katzir, Lasers Surg. Med., 2000, 26, 4-12.

180 D. Dew, L. Supik, C. Darrow 2nd and G. Price, Orthopedics, 1993, 16, 581-587.

181 J.-J. Kim, R. K. Singh, S.-J. Seo, T.-H. Kim, J.-H. Kim, E.-J. Lee and H.-W. Kim, RSC Adv., 2014, 4, 17325-17336.

182 C. Hoffmann, E. Mazari, S. Lallet, R. Le Borgne, V. Marchi, C. Gosse and Z. Gueroui, Nat. Nanotechnol., 2013, 8, 199-205.
183 M. Domenech, I. Marrero-Berrios, M. Torres-Lugo and C. Rinaldi, ACS Nano, 2013, 7, 5091-5101.

184 J. Choi, J. Shin, J. Lee and M. Cha, Chem. Commun., 2012, 48, 7474-7476.

185 J. M. Perez, J. Grimm, L. Josephson and R. Weissleder, Neoplasia, 2008, 10, 1066-1072.

186 H. Lee, T.-J. Yoon, J.-L. Figueiredo, F. K. Swirski and R. Weissleder, Proc. Natl. Acad. Sci. U. S. A., 2009, 106, 12459-12464.

187 J. Grimm, J. M. Perez, L. Josephson and R. Weissleder, Cancer Res., 2004, 64, 639-643.

188 M. C. Bautista, O. Bomati-Miguel, X. Zhao, M. P. Morales, T. González-Carreño, R. P. d. Alejo, J. Ruiz-Cabello and S. Veintemillas-Verdaguer, Nanotechnology, 2004, 15, S154.

189 J. M. Perez, L. Josephson, T. O’Loughlin, D. Högemann and R. Weissleder, Nat. Biotechnol., 2002, 20, 816.

190 E. I. Galanzha, E. V. Shashkov, T. Kelly, J. W. Kim, L. Yang and V. P. Zharov, Nat. Nanotechnol., 2009, 4, 855-860.

191 K. Shimizu, A. Ito, T. Yoshida, Y. Yamada, M. Ueda and H. Honda, J. Biomed. Mater. Res., Part B, 2007, 82B, 471-480. 